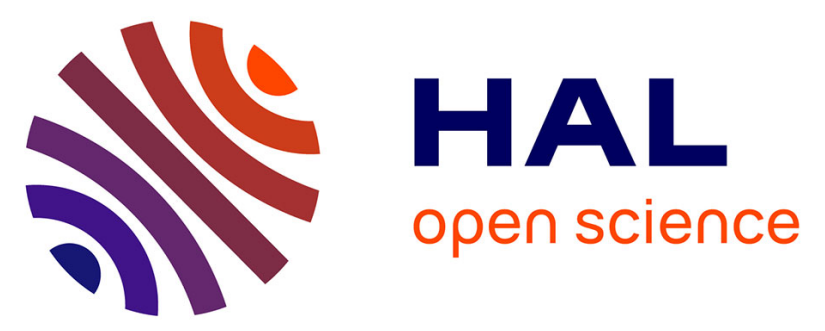

\title{
Understanding the biokinetics of ibuprofen after single and repeated treatments in rat and human in vitro liver cell systems.
}

Germaine L Truisi, Emma Di Consiglio, Céline Parmentier, Camille C Savary, Giuliana Pomponio, Frederic Bois, Birthe Lauer, Rozenn Jossé, Philip G Hewitt, Stefan O Mueller, et al.

\section{To cite this version:}

Germaine L Truisi, Emma Di Consiglio, Céline Parmentier, Camille C Savary, Giuliana Pomponio, et al.. Understanding the biokinetics of ibuprofen after single and repeated treatments in rat and human in vitro liver cell systems.. Toxicology Letters, 2015, 233 (2), pp.172-86. 10.1016/j.toxlet.2015.01.006 . hal-01134674

\section{HAL Id: hal-01134674 \\ https://hal-univ-rennes1.archives-ouvertes.fr/hal-01134674}

Submitted on 22 Apr 2015

HAL is a multi-disciplinary open access archive for the deposit and dissemination of scientific research documents, whether they are published or not. The documents may come from teaching and research institutions in France or abroad, or from public or private research centers.
L'archive ouverte pluridisciplinaire HAL, est destinée au dépôt et à la diffusion de documents scientifiques de niveau recherche, publiés ou non, émanant des établissements d'enseignement et de recherche français ou étrangers, des laboratoires publics ou privés. 
UNDERSTANDING THE BIOKINETICS OF IBUPROFEN AFTER SINGLE AND REPEATED TREATMENTS IN RAT AND HUMAN IN VITRO LIVER CELL SYSTEMS

5 Germaine L Truisi ${ }^{\mathrm{a}, \mathrm{b*}}$, Emma Di Consiglic ${ }^{\mathrm{c}}$, Céline Parmentier ${ }^{\mathrm{d} *}$, Camille C Savary ${ }^{\mathrm{e}}$, Giuliana 6 Pomponio $^{c}$, Frederic Bois ${ }^{\dagger}$, Birthe Lauer ${ }^{a}$, Rozenn Jossée, Philip G Hewitt ${ }^{a}$, Stefan O Mueller ${ }^{\mathrm{a}, \mathrm{b}}$, 7 Lysiane Richert ${ }^{\mathrm{d}, \mathrm{g}}$, André Guillouzo ${ }^{\mathrm{e}}$, Emanuela Testai ${ }^{\mathrm{c}}$ (1)

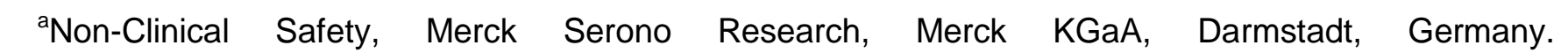
Germaine.Truisi@web.de, lauerbi@web.de, Philip.Hewitt@merckgroup.com, stefan.o.mueller@tonline.de

${ }^{\mathrm{b}}$ Institut für Angewandte Biowissenschaften, Karlsruhe Institute of Technology (KIT), Karlsruhe, Germany.

'Mechanism of Toxicity Unit, Environment and Primary Prevention Department, Istituto Superiore di Sanità, Rome, Italy.emma.diconsiglio@iss.it, giuliana.pomponio@gmail.com, emanuela.testai@iss.it 'KaLy-Cell, 20A Rue du Général Leclerc, Plobsheim, France.c.parmentier@kaly-cell.com, I.richert@kaly-cell.com

eInstitut National de la Santé et de la Recherche Médicale (Inserm), UMR991, Université de Rennes 1, Rennes, France.camille.savary@univ-rennes1.fr, rozenn.josse@gmail.com,andre.guillouzo@univrennes1.fr

'Institut National de L'Environnement Industriel et des Risques, DRC/VIVA/METO, Verneuil en Halatte, France.frederic.bois@utc.fr

'Laboratoire de Toxicologie Cellulaire, EA4267, Université de Franche-Comté, Besançon, France.

* These authors contributed equally to this work.

\section{Corresponding author: Emanuela Testai} Istituto Superiore di Sanità Viale Regina Elena 299 I-00161 Rome, Italy Phone: +39-06 49902920

Fax: +39- 0649387139

Email: emanuela.testai@iss.it 


\section{Abstract}

35 Common in vitro toxicity testing often neglects the fate and intracellular concentration of tested compounds, potentially limiting the predictability of in vitro results for in vivo extrapolation. We used in vitro long-term cultures of primary rat $(\mathrm{PRH})$ and human hepatocytes $(\mathrm{PHH})$ and HepaRG cells to characterise and model the biokinetic profile of ibuprofen (IBU) after single and daily repeated exposure (14 days) to two concentrations. A cross-model comparison was carried out at $100 \mu \mathrm{M}$, roughly corresponding to the human therapeutic plasma concentration. Our results showed that IBU uptake was rapid and a dynamic equilibrium was reached within 1 or 2 days. All three cell systems efficiently metabolised IBU. In terms of species-differences, our data mirrored known in vivo results. Although no bioaccumulation was observed, IBU intracellular concentration was higher in $\mathrm{PRH}$ due to a 10-fold lower metabolic clearance compared to the human-derived cells. In HepaRG cells, IBU metabolism increased over time, but was not related to the treatment. In $\mathrm{PHH}$, a low CYP2C9 activity, the major IBU-metabolising CYP, led to an increased cytotoxicity. A high inter-individual variability was seen in $\mathrm{PHH}$, whereas HepaRG cells and $\mathrm{PRH}$ were more reproducible models. Although the concentrations of IBU in $\mathrm{PRH}$ over time differed from the concentrations found in human cells under similar exposure conditions.

Keywords: Biokinetics, Ibuprofen, in vitro, Primary rat hepatocytes, Primary human hepatocytes, 52 HepaRG cells 


\section{Abbreviations}

55 ADR - adverse drug reaction

56 bcell - biliary cell

57 BSA - bovine serum albumin

$58 \quad \mathrm{C}_{\text {cell }}$ - concentration in cell lysate

$59 \mathrm{C}_{\max }$ - human therapeutic peak plasma concentration

$60 \quad \mathrm{C}_{\text {med }}$ - concentration in assay medium

61 CV- coefficient of variation

62 CYP - cytochrome P450

63 DME - drug metabolising enzyme

64 DMEM - Dulbecco modified eagle medium

65 DMSO - dimethyl sulphoxide

66 FBS - foetal bovine serum

$67 \quad F_{\text {in }}$ - entry rate flow for one cell

$68 F_{\text {out }}$ - exit rate flow for one cell

69 HMM - hepatocyte maintenance medium

70 IBU - ibuprofen

71 ITS - insulin transferrin selenium

$72 \mathrm{k}_{1}$ - rate constant for binding to medium proteins

$73 \mathrm{k}_{2}$ - rate constant for unbinding from medium proteins

$74 \quad \mathrm{~K}_{\mathrm{m}}$ - Michaelis-Menten constant

75 LOD- Limit of detection

76 LOQ - Limit of quantification

77 MCMC - Markov-chain Monte Carlo

$78 \mathrm{~N}_{\text {cell }}-$ number of cells in the assay system

79 NOAEC - No observed adverse effect concentration 
80 OECD - Organisation for Economic Co-operation and Development

$81 \mathrm{PHH}$ - primary human hepatocytes

82 PBPK - physiologically-based pharmacokinetics

$83 \mathrm{PRH}$ - primary rat hepatocytes

$84 \mathrm{Q}_{\text {cell }}$ - total quantity in cell lysate

$85 Q_{\text {med }}$ - total quantity in assay medium

$86 \mathrm{Q}_{\text {prot }}$ - total quantity bound on protein

87 SD - standard deviation

88 SW - sandwich

$89 \mathrm{t}_{1 / 2}$ - half-life

90 TC - toxic concentration

$91 \mathrm{~T}_{\max }$ - time to reach $\mathrm{C}_{\max }$

$92 \quad \mathrm{~V}_{\text {cell }}$ - volume of cells

$93 \quad \mathrm{~V}_{\max }-$ maximal metabolic rate

$94 \quad \mathrm{~V}_{\mathrm{med}}$ - volume of assay medium

95 


\section{Introduction}

97 Attrition during drug discovery and development is a major hurdle to the launch of a drug and lack of efficacy and unacceptable toxicity are the two major reasons (Kola and Landis, 2004). Usually, the potential risk for human health of pharmaceuticals is assessed in the early phases of development on the basis of animal testing. However, the extrapolation of observed adverse drug reactions (ADRs) from animals to humans is often difficult. The discrepancies can be frequently attributed to different kinetic behaviours of the compound in the different species (Shanks et al., 2009).

In the last decades, in vitro models have improved substantially, resulting in applications accepted as valuable tools to characterise and optimise compounds in terms of efficacy and safety. Most of these in vitro models apply a single exposure to deliver discrete information on single endpoints. By contrast, more complex in vitro models, for the identification of systemic effects, lack acceptance mainly because they poorly correlate with in vivo data (Adler et al., 2011). Differences between in vitro and in vivo kinetics have been considered as one of the main reasons. Despite this, the implementation of biokinetic information in in vitro systems has been mainly ignored. As a consequence, an observed effect indicated by e.g. $\mathrm{EC}_{50}$ (Effective Concentration causing the $50 \%$ of the effect) or NOAEC (No Observed Adverse Effect Concentration) in vitro is typically assigned to the applied nominal concentration of the test item, assuming that $100 \%$ is available within the cell. On the contrary, a number of abiotic processes affects the fraction of a test chemical that is available for uptake into cells or tissue, reducing its bioavailability. These processes include compound solubility, volatility, stability in aqueous solutions, binding to membrane lipids and proteins in cell culture medium or adsorption to plastic devices. Furthermore, biotic processes, such as mechanisms of cell uptake/extrusion, metabolism, intracellular bioaccumulation (of parent and/or metabolites) as well as saturation of these processes can influence the compound's biokinetic behaviour, affecting the biologically effective dose of test chemical, able to interact with the target or cause toxicity. This hampers the interpretation of in vitro data to predict in vivo dose-response relationships and compare the true toxic potency of test compounds (Groothuis et al, 2013). Thus, the intracellular concentration is a much more relevant 
parameter to enable the derivation of a NOAEC in vitro. This NOAEC can be then transformed to in vivo doses using appropriate modelling techniques, such as physiologically-based pharmacokinetics (PBPK) modelling.

Previous groups have shown that adsorption to plastic devices (Tirelli et al., 2007), binding to macromolecules in the medium (Guelden et al., 2001; Seibert et al., 2002), evaporation of the chemical (Kramer et al. 2012) and the number of cells in the cell system (Guelden et al., 2001; Guelden et al., 2010) influence the actual biologically effective concentration and thus the cytotoxic potential of a compound. A recent paper reviewed a number of factors affecting bioavailability of test chemicals in in vitro assays and different dose metrics for in vitro setups (Groothuis et al, 2013).

To further support this concept, the application of a recently developed model to a set of hypothetical chemicals as well as to 1194 real substances (predominantly from the ToxCast chemical database) shows that the potential range of concentrations and chemical activities under assumed test conditions can vary by orders of magnitude for the same nominal concentration (Armitage et al. 2014). There is an urgent need for predictive in vitro models to identify ADRs in the early phases of drug development, especially for the liver. As the main drug metabolising organ, the liver plays a central role in drug-induced toxicities. Furthermore, repeated drug administration is a more relevant exposure scenario for therapeutics, being usually evaluated in specified in vivo repeated-dose toxicity testing. In order to mimic repeated exposures in vitro, models retaining in vivo characteristics for a sufficiently long time frame should be used. Both hepatotoxicity and repeated exposure were addressed in this work by using different long-term hepatic culture systems.

Primary hepatocytes are the gold standard for metabolism studies because these cells retain in vivo143 like activities of drug metabolising enzymes (DMEs) (Guillouzo, 1998; Hewitt et al., 2007; Tuschl et al., 144 2008). However, monolayer cultures of primary hepatocytes lose the activity of some liver-specific 145 enzymes within a few days (Guillouzo, 1998; Tuschl et al., 2009). By contrast, primary rat and human 146 hepatocytes ( $\mathrm{PRH}$ and $\mathrm{PHH}$, respectively) cultured in a sandwich (SW) configuration with defined 147 medium, maintain their metabolic capacities at acceptable levels over a prolonged time period 
148 (Parmentier et al., 2013; Tuschl et al., 2009). The cholangio-hepatocarcinoma derived cell line 149 HepaRG $^{\mathrm{TM}}$ has proven itself valuable for many applications, including the prediction of metabolism150 dependent hepatotoxicity (Aninat et al., 2006; Anthérieu et al., 2012). This human-derived cell line is a 151 promising system, because after proliferation and differentiation phases it holds adequate and rather 152 stable activity of DMEs throughout long-term culture.

153 The EU FP7 Project Predict-IV aimed to provide an improved predictability of the non-clinical safety 154 testing by using in vitro tests, proposed to integrate dynamics and biokinetics in in vitro models after 155 repeated exposure. This paper describes some of the obtained results comparing the three hepatic 156 models described above to study the kinetic behaviour of ibuprofen (IBU), after acute and long-term 157 repeated treatment.

158 IBU, a non-steroidal anti-inflammatory drug, seldom inducing ADRs in the liver, has been used as 159 model compound, selected on the basis of its physicochemical and metabolic properties.

160 To the best of our knowledge the in vitro biokinetics after single (d0/1) and repeated exposures $161(\mathrm{~d} 13 / 14)$ of a drug are here described for the first time. The integration of biokinetics to well162 established rat and human long-term liver culture systems addresses most of the current issues of in 163 vitro systems described above. The approach further includes the application of PK modelling, by 164 integrating the kinetic experimental parameters obtained in the different in vitro systems, and being a 165 fundamental tool for the extrapolation of in vitro data to the in vivo situation. 


\section{Materials and Methods}

168

169

170

171

172

173

174

175

176

177

178

179

180

181

182

183

184

185

186

187

188

189

190

191

192

\subsection{Chemicals and Reagents}

IBU was purchased from Sigma-Aldrich (Steinheim, Germany; St. Quentin-Fallavier, France) or Calbiochem (Darmstadt, Germany). For the culture of the $\mathrm{PRH}$ in sandwich configuration Collagen from rat tail tendon (Roche, Mannheim, Germany) was used, while PHH were covered with Geltrex ${ }^{\mathrm{TM}}$ from Gibco® (Thermo Fisher Scientific, Illkirch, France). The perfusion buffer components were from Merck Chemicals (Merck KGaA) and AppliChem (both Darmstadt, Germany) or Sigma-Aldrich (Steinheim, Germany; St. Quentin-Fallavier, France). DMEM/F12 GlutaMAX TM, Williams' E medium, Sodium-pyruvate, ITS-G (100x), Gentamycin, Glutamine, Trypsin/EDTA and PBS were obtained from Gibco® (LifeTechnologies, Darmstadt, Germany; Thermo Fisher Scientific, Illkirch, France). The culture medium, HMM, used with PHH was purchased from Lonza (Verviers, Belgium). Foetal bovine serum (FBS) was from HyClone®, Gibco® or Perbio (Thermo Fisher Scientific, Waltham (MA), USA or Illkirch, France); hydrocortisone hemisuccinate was from Upjohn Pharmacia (Guyancourt, France). Further reagents were from Sigma-Aldrich (Steinheim, Germany; St. Quentin-Fallavier, France) included penicillin/streptomycin, insulin, BSA, dexamethasone, percoll® and DMSO.

For IBU quantification analytical grade chemicals were obtained from commercially available sources. The Milli-Q water purification system (Millipore, Merck KGaA, Darmstadt, Germany) was used to obtain deionised water.

\subsection{Cell culture}

\subsubsection{Primary rat hepatocytes}

Care and use of laboratory animals was in agreement with the German guidelines and approved by the ethics committee. Isolation of rat hepatocytes from male Wistar rats (Harlan Laboratories, Rossdorf, Germany) followed a modified two-step perfusion technique described by Seglen (Seglen, 1976). Overall, only hepatocyte preparations with more than $85 \%$ viability (determined via trypan exclusion method) were used. 30,000 viable cells were seeded onto collagen I coated 96-well plates in serum-containing culture media (DMEM/F12 GlutaMAX'TM, 100 units/mL penicillin, $100 \mu \mathrm{g} / \mathrm{mL}$ 
streptomycin, $1 \mathrm{mM}$ sodium pyruvate, $10 \%$ FBS and $5 \mu \mathrm{g} / \mathrm{mL}$ insulin). Following an attachment phase

194 of $4 \mathrm{~h}$ the culture medium was replaced with serum-free culture medium media (DMEM/F12 195 GlutaMAX'⿳亠口冋, 100 units $/ \mathrm{mL}$ penicillin, $100 \mu \mathrm{g} / \mathrm{mL}$ streptomycin, $1 \mathrm{mM}$ sodium pyruvate, $100 \mathrm{nM}$ 196 dexamethasone, $0.44 \mathrm{mg} / \mathrm{L}$ BSA, ITS-G) and IBU treatment was started $24 \mathrm{~h}$ after seeding. For the 197 SW culture format, the cells were seeded in serum-containing culture media on a gelatinised layer of 198 collagen (prepared at $37^{\circ} \mathrm{C} \geq 1 \mathrm{~h}$ ) at a density of 0.25 and $1.5 \times 10^{6}$ viable cells per well in a 24- and 6199 well plate (BD Falcon ${ }^{\mathrm{TM}}$, Heidelberg, Germany), respectively. After four hours the culture medium was 200 replaced with fresh serum-containing media. On the subsequent day the top collagen stratum was 201 applied and after its full gelatinisation (at $37^{\circ} \mathrm{C} \geq 1.5 \mathrm{~h}$ ) serum-free culture medium media was added. 202 IBU treatment started on day 3 after seeding.

\section{$203 \quad$ 2.2.2 Primary Human Hepatocytes}

204 All experiments were performed with permission of the National Ethics Committee (France) and 205 regulatory authorities. Liver biopsies $(20-100 \mathrm{~g})$ were received from surgical operations of patients with 206 different pathologies (Table 1), whereas the obtained tissue was removed with a safety margin from 207 the aberrant section. LeCluyse and Alexandre (2010) delineate the two-step perfusion procedure 208 which was applied to isolate the $\mathrm{PHH}$ from the liver resections.

Viability of the PHH suspension, obtained directly after isolation, was assessed via trypan blue exclusion method and only preparations holding viability greater than $70 \%$ were used for cell culture experiments. The cells were seeded at a density of $2 \times 10^{6}$ viable cells per well of a collagen-coated 6well BD Biocoat® plate (Dutscher, France) for kinetic studies or at a density of $0.3 \times 10^{6}$ viable cells 213 per well of a 24-well plate (Biocoat ${ }^{\circledR}$, Dutscher, France) for CYP450 activity measurements. The 214 seeding medium was Williams' E medium containing $50 \mu \mathrm{g} / \mathrm{mL}$ gentamycin, 10\% $\mathrm{FBS}, 1 \mu \mathrm{M}$ 215 dexamethasone and $4 \mu \mathrm{g} / \mathrm{mL}$ insulin. Following an overnight incubation the monolayer culture was 216 covered with a preparation of $350 \mu \mathrm{g} / \mathrm{mL}$ Geltrex ${ }^{\mathrm{TM}}$ in serum-free culture media (HMM, $50 \mu \mathrm{g} / \mathrm{mL}$ 217 gentamycin, $100 \mathrm{nM}$ dexamethasone and 1x ITS-G). The Geltrex ${ }^{\mathrm{TM}}$ overlay was renewed every 3-4 218 days. IBU treatment was started two days after seeding. 


\subsubsection{HepaRG cells}

220 The liver tumour derived HepaRG cells were cultured and differentiated as previously described by 221 Gripon et al. (2002). Briefly, the HepaRG cells (at passage 12) were cultured in growth medium 222 (Williams' E supplemented with 10\% FBS, 100 units $/ \mathrm{mL}$ penicillin, $100 \mu \mathrm{g} / \mathrm{mL}$ streptomycin, $5 \mu \mathrm{g} / \mathrm{mL}$ 223 insulin, $2 \mathrm{mM}$ glutamine, and $50 \mu \mathrm{M}$ hydrocortisone hemisuccinate), which was refreshed three times 224 a week. After two weeks the growth medium was supplemented with $2 \%$ DMSO for additional two 225 weeks, resulting in differentiated HepaRG cell cultures. At that time the cultures contained hepatocyte226 like and primitive biliary cells at around the same percentage (Cerec et al., 2007; Aninat et al., 2006) 227 and were ready for treatment with IBU. Two days before treatment start the cells ( $2 \times 10^{6}$ per well) were 228 shifted to a medium containing $2 \%$ FBS and $1 \%$ DMSO. The percentage of FBS was lowered to $2 \%$ to 229 minimise protein binding of the test item, without altering the cell viability and functionality (data not 230 shown).

\subsection{Determination of CYP450s activity in PHH}

232 Basal CYP450s activities were determined in $\mathrm{PHH}$ cultures from the three donors used for kinetic 233 experiments. After attachment, cell monolayers were washed with warm phosphate buffered saline 234 (PBS) during $15 \mathrm{~min}$ at $37^{\circ} \mathrm{C}$, and thereafter incubated at $37^{\circ} \mathrm{C}$ under air/CO2 (95/5 \%) in DMEM with 235 Glutamax I supplemented with insulin $(4 \mathrm{mg} / \mathrm{mL})$, dexamethasone $(1 \mu \mathrm{M})$ and antibiotics, containing 236 the substrates as a cocktail: $3 \mu \mathrm{M}$ midazolam, $100 \mu \mathrm{M}$ bupropion and $10 \mu \mathrm{M}$ diclofenac for CYP3A4/5, 237 CYP2B6 and CYP2C9 respectively, as described by Kanebratt et al. (2008) or with ethoxyresorufin for 238 CYP1A1/2. At the end of the incubation period, supernatants were collected and stored at $-80^{\circ} \mathrm{C}$ until analysis. The metabolites midazolam 1'-hydroxylation (CYP3A4/5), diclofenac 4-hydroxylation (CYP2C9) and bupropion-hydroxylation (CYP2B6) were determined by LC-MS/MS and resorufin by fluorescence, as described by Alexandre et al. (2012).

\subsubsection{Stability and solubility of the test compound}


244 The stability of IBU in both aqueous solutions and in DMSO (the vehicle used to prepare stock 245 solutions), was checked in preliminary assays, mimicking the actual experimental conditions. Distilled 246 water, culture media and IBU solutions in DMSO were kept at $37^{\circ} \mathrm{C}$ for different incubation times in 247 glass lab-wear and plastic tubes and analysed by HPLC.

\section{$248 \quad 2.4 .2 \quad$ Cross-contamination among wells}

249 In the adjacent wells to those containing IBU at the applied concentrations, a corresponding amount of 250 DMSO (vehicle control) was added. At the end of the experiment, the content of these control wells 251 was stored at $-80^{\circ} \mathrm{C}$ until HPLC analysis. The IBU content in these control wells served as an 252 indication of possible contamination across wells due to IBU evaporation.

\section{$253 \quad 2.4 .3 \quad$ Adsorption to plastic devices}

254 In order to measure adsorption to the plastic, once the content of each well was removed, the wells 255 were washed twice with PBS before adding $2 \mathrm{~mL}$ methanol. The plate was sealed with Parafilm, and 256 kept on a horizontal shaker $(350 \mathrm{rpm})$ at room temperature for $2 \mathrm{~h}$ before transferring the complete 257 volume into a LoBind tube.

\section{$258 \quad 2.5$ Sequestration by the matrix}

259 To determine the amount of IBU possibly sequestered by proteins in the collagen or Geltrex ${ }^{\mathrm{TM}}$ matrix $^{\mathrm{T}}$ 260 used for $\mathrm{PRH}$ and $\mathrm{PHH}$ SW cultures, repeated exposure experiments were conducted with the same schedule of the main experiment but in the absence of cells ('blank experiment'). Here, corresponding 262 volumes of collagen I $(\mathrm{PRH})$ and Geltrex ${ }^{\mathrm{TM}}(\mathrm{PHH})$ were exposed to high and low IBU concentrations or DMSO vehicle control. Sampling was performed on the first (0/1) and last (13/14) day of treatment, at two time points (2 $\min$ and $24 \mathrm{~h})$.

\subsection{Assessment of cell viability after IBU exposure}

Preliminary experiments were performed to determine the cytotoxicity of IBU. For all applied assays, the results were expressed as a percentage versus the vehicle treated control. In $\mathrm{PRH}$, the dose finding was performed in three stages (Table 2), starting with treatment with a broad 
replicates in 24-well plate SW culture were treated for 1,3 and 14 days to assess a preliminary $\mathrm{TC}_{10}$

271 (the concentration causing 10\% cytotoxicity, in the specific case measured as ATP depletion). Finally, 272 three concentrations around the determined $\mathrm{TC}_{10}$ were tested in 6-well plate $\mathrm{SW}$ cultures, the format 273 for the final experiments, for 14 days repeated exposure.

274 The cell viability was determined via ATP levels that were measured using the CellTiter-Glo® 275 Luminescent Cell Viability Assay (Promega®) according to the manufacturer's protocol including slight 276 modifications. Briefly, after the corresponding exposure time cell cultures in 96-, 24- or 6-well plates 277 were incubated with $100 \mu \mathrm{L}, 600 \mu \mathrm{L}$ or $900 \mu \mathrm{L}$ CellTiter-Glo® Reagent for 2 min on an orbital shaker. 278 After 10 min the luminescence signal was measured.

279 In PHH, preliminary assessment of IBU cytotoxicity was performed in one culture (donor S0302V, not 280 further used for kinetic testing): $0.05 \times 10^{6}$ viable cells were seeded onto collagen I coated 96-well 281 Biocoat ${ }^{8}$ plates (Dutscher, France) in Williams' E medium supplemented with $10 \% \mathrm{FBS}, 4 \mu \mathrm{g} / \mathrm{mL}$ 282 insulin, $1 \mu \mathrm{M}$ dexamethasone and $50 \mu \mathrm{g} / \mathrm{mL}$ gentamycin. Following an overnight incubation, the cell 283 284 285 286 287 288 289 290 291 292 monolayer was covered with $350 \mu \mathrm{g} / \mathrm{mL}$ Geltrex ${ }^{\mathrm{TM}}$ in culture medium without FBS for $24 \mathrm{~h}$. Six IBU concentrations were tested, corresponding to the concentrations applied to PRH in 24-well SW cultures (see Table 2). A MTT test was performed after 1, 3 and 14 days of treatment. Here, cells were incubated with $1 \mathrm{mg} / \mathrm{mL}$ thiazolyl blue tetrazolium bromide for $30 \mathrm{~min}$, the supernatant was replaced by $100 \mu \mathrm{L}$ DMSO per well. After gentle shaking, the absorbance was measured at $595 \mathrm{~nm}$.

For IBU cytotoxicity determinations, $2.5 \times 10^{5} \mathrm{HepaRG}$ cells were seeded per well in 96-well plates as described previously (Aninat et al., 2006). Briefly, after 1, 3 and 14 days of treatment, medium was removed and serum-free medium containing MTT $(0.5 \mathrm{mg} / \mathrm{mL})$ was added to each well and incubated for $2 \mathrm{~h}$ at $37^{\circ} \mathrm{C}$. After removal of the incubation solution, water-insoluble formazan was dissolved in DMSO and absorbance was measured at $540 \mathrm{~nm}$.

\subsection{IBU exposure for kinetic experiments}

On the basis of results obtained from the preliminary cytotoxicity tests, the two IBU concentrations used during the kinetic experiments in the three cell culture systems were set as follows: the $\mathrm{TC}_{10}$ in 
296 the corresponding hepatic system, to reveal underlying mechanisms of toxicity, without causing a 297 significant decrease in the number of cells; $1 / 10 \mathrm{TC}_{10}$, which should give an insight into 298 pharmacological actions of the drug on cellular level. Eventually, the applied IBU treatment 299 concentrations were $10 \mu \mathrm{M}$ and $100 \mu \mathrm{M}$ in PRH and HepaRG cells, and $100 \mu \mathrm{M}$ and $1000 \mu \mathrm{M}$ in $\mathrm{PHH}$. 300 Prior to each experiment IBU stock solutions (500- or 1000-fold) were prepared in DMSO and stored 301 at $-20^{\circ} \mathrm{C}$ until needed. Treatment solutions were prepared by diluting the IBU stocks (50 mM and 5 $302 \mathrm{mM}$ for $\mathrm{PRH}$ and $500 \mathrm{mM}$ and $50 \mathrm{mM}$ for $\mathrm{PHH}$ ) 1:500 in serum-free culture medium, keeping DMSO 303 concentration at $0.2 \%$. The stock solutions (100 mM and $10 \mathrm{mM})$ for the HepaRG cells were diluted 304 (1:1000) in medium containing 1\% DMSO and 2\% FBS to obtain ready-to-use solutions. Aliquots of 305 the daily treatment solution (considered as time 0 samples) and of the stock solutions were stored at $306 \quad 80^{\circ} \mathrm{C}$ until HPLC analysis.

307 Cell treatment with IBU $\mathrm{TC}_{10}$ and $1 / 10 \mathrm{TC}_{10}$ was initiated by adding $1.5 \mathrm{~mL}(\mathrm{PRH})$ or $2 \mathrm{~mL}(\mathrm{PHH}$ and 308 HepaRG cells) per well of the corresponding ready-to-use solutions or the vehicle (control wells). Per 309 definition, the day of the first exposure was referred to as day 0 and media were changed on a daily 310 basis for 14 days.

\subsection{Sample preparation for HPLC analysis}

312 A sample of cell culture media at time $0 \mathrm{~min}\left(\mathrm{t}_{0}\right)$ to verify the actual IBU concentration added to the 313 well, and samples of supernatant and cell lysate were collected on day 0/1 and day 13/14 at 5 different 314 time points (TP): 2 min, $30 \mathrm{~min}, 1 \mathrm{~h}, 3 \mathrm{~h}$ and $24 \mathrm{~h}$ for $\mathrm{PRH}$ and $\mathrm{PHH}$. In parallel, samples to measure 315 plastic adsorption were prepared on empty wells, as described above. The TP selection was based on 316 intrinsic characteristics of IBU (e.g. 90-99\% protein binding, rapid metabolism with half-life 2-4 hours) 317 and the cell systems (e.g. metabolic competence). The a priori selected TP were confirmed in a 318 preliminary experiment for $\mathrm{PRH}$ and $\mathrm{PHH}$, whereas for HepaRG cells uptake into the cells was 319 delayed. Therefore, to get a better description of the kinetic behaviour in HepaRG cells, the initially 320 selected TP were changed to $30 \mathrm{~min}, 1 \mathrm{~h}, 3 \mathrm{~h}, 6 \mathrm{~h}$ and $24 \mathrm{~h}$. 
321 At the selected TP, the supernatant was pipetted into LoBind tubes, and cells were washed twice with 322 PBS. The SW cultured PRH and PHH were scraped and transferred into a new LoBind tube; the well 323 was rinsed with $250 \mu \mathrm{L}$ methanol, which was added to the same tube. Finally, the cell lysate was 324 homogenised using an in-probe sonicator and the volume was adjusted with methanol to $1 \mathrm{~mL}$. 325 HepaRG cells were scraped in $200 \mu \mathrm{L}$ PBS and transferred into a new LoBind tube containing $600 \mu \mathrm{L}$ 326 Methanol. A volume of $200 \mu \mathrm{L}$ PBS was used to wash the well and after adding it to the same tube, 327 the cell lysate was homogenised (in-probe sonication). All fractions were stored at $-80^{\circ} \mathrm{C}$ until HPLC 328 analysis.

\section{$3292.9 \quad H P L C$ analysis of IBU}

330 Methanol was selected as the extraction solvent after checking extraction efficiency: IBU recovery 331 from the 3 media and HepaRG cell lysate was > 95\%; for $\mathrm{PRH}$ and $\mathrm{PHH}$ cell lysate for which the 332 recovery was $\sim 75 \%$ an appropriate correction factor was applied for the calculation of IBU content.

333 Three times volumes methanol were added to the supernatant collected at $t_{0}$ and at different TP; the 334 mixture was vortexed for $30 \mathrm{~s}$. All samples, including cell lysates, were centrifuged (Eppendorf 5417R; $\left.3355 \mathrm{~min}, 4^{\circ} \mathrm{C}, 2500 \mathrm{rpm}\right)$; the upper phase was transferred into amber glass vials for HPLC analysis.

336 The HPLC system included a PerkinElmer Series 200 analytical pump, a Restek ${ }^{\mathrm{TM}}$ Pinnacle ODS 337 Amine C18 column, a PerkinElmer LC 235 Diode Array Detector and the PerkinElmer Totalchrom ${ }^{\mathrm{TM}}$ 338 3.1.2 software for data acquisition and evaluation. IBU identification and quantification was based on 339 the isocratic method described by Hassan et al. (2008) with minor modifications, yielding a better 340 resolution capacity. The method was specific for IBU and not able to detect its major oxidative 341 metabolites $(\mathrm{OH}-$ and $\mathrm{COOH}-\mathrm{IBU})$ and the glucuronides (data not shown). The mobile phase 342 consisted of a 60:40 (v/v) mixture of methanol and NaH2PO4 (50 mM, pH 6.5), at a flow rate of 0.6 $343 \mathrm{~mL} / \mathrm{min}$. The injection volume was $20 \mu \mathrm{L}$. The absorption of the eluate was measured continuously at $344220 \mathrm{~nm}$ (retention time $17 \mathrm{~min}$ ); the amount of IBU was quantified referring to a calibration straight line 345 (8 concentrations in triplicate, range 1-250 $\mu \mathrm{M}$; correlation coefficient R2 = 0.978; LOD = 6.2 nM, LOQ $346=20.6 \mathrm{nM}, \mathrm{CV}=4.5 \%)$ 
347 In order to have comparable results across the three biological replicates, the raw data obtained in this 348 study were normalised against the cell number per well. However, cells/well did not vary significantly 349 among the different wells, as determined by measuring protein content (in $\mathrm{PHH}$ ), or detaching 350 HepaRG cells and counting the number per well (in separate wells close to the ones used for the 351 kinetic analysis), or by high content imaging in separate plates (in PRH) (data not shown); hence, the 352 IBU content in different compartments was expressed as nmol per well.

\section{$353 \quad 2.10$ Pharmacokinetic Modelling}

354 To describe the in vitro pharmacokinetics of IBU, we adapted a three-compartment dynamic model as 355 previously developed for cyclosporine A (Wilmes et al., 2013). The model describes the change in 356 time of the total quantity of IBU in the assay medium $\left(Q_{\text {med }}\right)$, in cells lysate $\left(Q_{\text {cell }}\right)$ and bound on 357 proteins such as collagen, if present, $\left(Q_{\text {prot }}\right)$ in the assay system (Figure 1). The model is generic for 358 simple static system and therefore can be applied to different in vitro models as it was shown within 359 the Predict-IV project with appropriate adjustments. The approach is not dissimilar to the one recently 360 published by Armitage et al. (2014), which is a steady-state approximation of an in vitro system easy 361 to compute and suitable for high throughput analyses. Since our goal was to perform a kinetic 362 analysis, we developed a dynamic model, including more parameters and their calibration, generating 363 a higher degree of precision in estimates.

364 No adsorption to plastic vial walls was included, as the obtained experimental data with the three 365 models showed that none occurred for IBU or that it was negligible. Due to sequestration by collagen, 366 for PRH the "multiple binding" processes to medium proteins, collagen walls were modelled as a single process. For $\mathrm{PHH}$ and HepaRG cells there was no evidence of non-specific binding from the blank experiments, thus it was neglected..

Since the experimental data showed that IBU can be metabolised within cells, biotransformation was accounted for in the model. The following three differential equations correspond to the general form of that model: 
$\frac{d Q_{\text {med }}}{d t}=N_{\text {cell }}\left(F_{\text {out }} C_{\text {cell }}-F_{\text {in }} C_{\text {med }}\right)+k_{2} Q_{\text {prot }}-k_{1} Q_{\text {med }}$

373

$C_{\text {med }}=\frac{Q_{\text {med }}}{V_{\text {med }}}$

374

$C_{\text {cell }}=\frac{Q_{\text {cell }}}{N_{\text {cell }} V_{\text {cell }}}$

375

376

377 378

379

380

$\frac{d Q_{\text {cell }}}{d t}=N_{\text {cell }}\left(F_{\text {in }} C_{\text {med }}-F_{\text {out }} C_{\text {cell }}-\frac{V_{\text {max }} Q_{\text {cell }}}{K_{m}+Q_{\text {cell }}}\right)$

381 where $V_{\max }$ is maximal rate of metabolism and $\mathrm{K}_{\mathrm{m}}$ the metabolism Michaelis-Menten constant. In Eq. 5 382 a cell volume proportionality difference was used in the definition of $\mathrm{K}_{\mathrm{m}}$ rather than concentrations, 383 with no change in the results. The cell volume used for the conversion was $6700 \mu \mathrm{m}^{3}$ for 384 PRH(experimentally determined in-house) and $3400 \mu \mathrm{m}^{3}$ for PHH and HepaRG cells (2000). Details of 385 the parameters used for the modelling are given in Tables S1 and S2 (Supplementary material).

For each model the best fit for exchange rates were used: For PRH, the best fit was obtained using 387 first order rates for collagen binding and unbinding, cell entry and exit rate and metabolism (the range 388 of concentration assayed did not include doses high enough to identify a maximum rate of 389 metabolism). For PRH model Eq. 5 above was therefore replaced by its first order equivalent: 390

$$
\frac{d Q_{\text {cell }}}{d t}=N_{\text {cell }}\left(F_{\text {in }} C_{\text {med }}-F_{\text {out }} C_{\text {cell }}-\frac{V_{\text {max }}}{K_{m}} Q_{\text {cell }}\right)
$$


392 For $\mathrm{PHH}$, no binding to GelTrex ${ }^{\mathrm{TM}}$ was observed and its rate was set to zero, first order cell entry and 393 exit rate and saturable metabolism gave the best fit.

394 For HepaRG cells, the model considers that a large number of biliary cells develop are present in the 395 cell culture. These cells do not metabolise IBU which on the other hand we assumed as able to enter 396 or exit them, at about the same rate per cell as in hepatocytes. We therefore added an equation to 397 describe the potential accumulation of IBU in biliary cells (express as $\mathrm{Q}_{\mathrm{bcell}}$ ). In addition, metabolism is 398 known to increase with time in HepaRG cells (Anthérieu et al., 2010) so we described it as a time399 varying first order process. The HepaRG PK model was therefore:

$$
\frac{d Q_{\text {med }}}{d t}=N_{\text {cell }}\left(F_{\text {out }} C_{\text {cell }}-F_{\text {in }} C_{\text {med }}\right)+N_{\text {bcell }}\left(F_{\text {out }} C_{\text {bcell }}-F_{\text {in }} C_{\text {med }}\right)+k_{2} Q_{\text {prot }}-k_{1} Q_{\text {med }}
$$

403 where $\mathrm{N}_{\mathrm{bcell}}$ is the number of biliary cells in the assay system and $\mathrm{C}_{\mathrm{bcell}}$ the concentration of IBU in 404 those cells.

405 To fit the model parameters, statistical distributions of their values were obtained by Bayesian 406 numerical calibration (Bois, 2009) with the experimental data provided by the experiments described 407 above. The doses actually measured were used as input to the model, rather than the nominal doses. 408 As usually done with concentration measurements, the data were assumed to be log-normally 409 distributed with geometric means given by the corresponding model predictions and geometric 410 variances sampled from half-normal distributions. Markov-chain Monte Carlo (MCMC) simulations 411 were performed with GNU MCSim version 5.5 .0 (http://www.gnu.org/software/mcsim). Two MCMC 412 chains were run in parallel for 50,000 iterations. Their convergence was checked on the last 25,000 413 iterations using the criterion of Gelman and Rubin (1992). In the case of $\mathrm{PHH}$, there were clear 414 differences between donors, so a hierarchical populations model was used to disentangle variability 415 from uncertainty in parameter estimation (Gelman et al., 1996; Bauer and Guzy, 2007; Bois et al., 416 2010). Briefly, each 14-day cell culture was fitted individually, yielding one set of parameters for each. 417 However, to stabilize inference and pool information between individual cultures, individuals' 
418 parameter values were supposed to vary following predefined non-uniform distributions. We used log 419 normal distributions. For example, in the case of $\mathrm{PHH}$ the cell entry flow rate was supposed to vary log 420 normally around a "population" mean (unknown, to be estimated together with the individual values) 421 with an estimated "population" geometric variance. In the end, a set of parameters was obtained for 422 each individual culture, one set of "population" averages and one set of "population" variances. The 423 (geometric) population means themselves were specified with the prior distributions given in Table 5. 424 The (geometric) population variances were assigned half-normal prior distributions.

425 Numerical integration of the models was performed with GNU MCSim version 5.5.0. Plots were 426 produced with $\mathrm{R}$, version 2.14.0.

427

$428 \quad 3 \quad$ Results

$429 \quad 3.1 \quad$ Abiotic processes

430 IBU was soluble even at the highest used concentration (i.e. stock solutions), both in the vehicle and 431 in the culture media, with recovery of known amount of IBU after solubilisation in the range of 97$432116 \%$. IBU was chemically stable under the experimental conditions used (i.e. incubation time, 433 temperature, DMSO and different culture media), with the recovery of known amount of IBU in the 434 range of $92-115 \%$, in glass labware and $94-110 \%$ in plastic tubes. In line with this and IBU's low 435 lipophilicity at $\mathrm{pH} 7.4\left(\log \mathrm{K}_{\mathrm{OW}}=0.8\right)$, IBU did not adsorb to the plastic devices used during testing as 436 shown by no IBU extracted by methanol in the ad hoc assays, and mass balance close to $100 \%$ at the 437 first TP during kinetic experiments (see Figures 2-4, E and F). The media used in the three models 438 contain a sodium-bicarbonate buffer system, which in a $5 \% \mathrm{CO}_{2}$ environment, and maintain an almost 439 constant $\mathrm{pH}$ in the physiological range, not altering IBU ionized state during the 14 days of treatment 440 and hence also its lipophylicity $\left(\log \mathrm{K}_{\mathrm{ow}}=2.48-3.30\right.$ at $\left.\mathrm{pH} 5\right)$.

441 No evaporation leading to cross-contamination among wells occurred, in accordance with IBU low 442 volatility (vapour pressure: $7.08 \times 10^{-3} \mathrm{~Pa}$ at $25^{\circ} \mathrm{C}$ ). 
443 The potentially significant IBU protein binding in the culture media ( 99\%; Rainsford 2009) was limited 444 by avoiding the use of serum with $\mathrm{PRH}$ (replaced with $0.44 \mathrm{mg} / \mathrm{mL} \mathrm{BSA}$ ) and $\mathrm{PHH}$ experiments and 445 using $2 \%$ FBS (corresponding to $0.8-0.9 \mathrm{mg} / \mathrm{mL}$ albumin), in HepaRG cell experiments. This condition 446 did not alter HepaRG cell viability and performance. and was demonstrated not to affect the uptake of 447 amiodarone, a drug with protein binding capacity similar to IBU (Pomponio et al, 2014). IBU recovery $448(110 \pm 10 \%)$ from the medium was not influenced by BSA or FBS.

449 In blank experiments, results showed that collagen I (used with $\mathrm{PRH}$ ) sequestered IBU in a time- and 450 concentration-dependent manner (Table 3). IBU levels in collagen increased on d0 up to $15 \%$ after 24 451 h. On d13, the percentages levelled off at around $30 \%$ at each time point and concentration, 452 suggesting a saturation of the extracellular matrix. A fraction of the added concentration (content of $t_{0}$ 453 media) of 15 and $30 \%$, on $\mathrm{d} 0$ and $\mathrm{d} 13$, respectively, were factored into the intracellular IBU 454 concentrations. Amounts $<5 \%$ of the nominal concentrations were within the experimental variance 455 and hence were not taken into consideration, also in view of the absence of cells, which are thought to 456 compete with collagen.

457 Analyses of Geltrex ${ }^{\mathrm{TM}}$ preparations (used with $\mathrm{PHH}$ ) showed that negligible binding of IBU to the 458 matrix molecules was found even after repeated exposure with $1000 \mu \mathrm{M}$. In accordance with these 459 findings, IBU detected in the corresponding supernatants was in the range $95-108 \%$.

460

\subsection{Kinetic profile of IBU in PRH}

462 The analyses of cell culture media at $\mathrm{t}_{0}$ revealed that a mean of $8.7 \pm 0.7 \mu \mathrm{M}$ and $85.3 \pm 10.3 \mu \mathrm{M}$ were 463 applied vs. a nominal concentrations of $10 \mu \mathrm{M}$ and $100 \mu \mathrm{M}$, respectively, with a CV of 8-12\% $(\mathrm{N}=20$ 464 per concentration).

465 At $10 \mu \mathrm{M}$ (low concentration) a similar IBU kinetic profile was observed on d0 and d13 both for the cell 466 lysate and the supernatant compartments (Figure 2, A and B), indicating that the repeated treatment 467 did not result in any saturation, inhibition or induction phenomena. A rapid and progressive 468 intracellular uptake of IBU was evident from 2 min to $1 \mathrm{~h}$. After a steady state from 1 to $3 \mathrm{~h}$ the amount 
469

470

471

472

473

474

475

476

477

478

479

480

481

482

483

484

485

486

487

488

489

490

491

492

493

494

of IBU in the cell lysates decreased up to $24 \mathrm{~h}$ (Figure 2, A). In parallel, a non-proportional decrease was observed over time in the supernatant, indicating a steady state from 1 to $3 \mathrm{~h}$ followed by a drop to 3 and $12 \%$ of applied IBU at $24 \mathrm{~h}$ of $\mathrm{d} 0$ and $\mathrm{d} 13$, respectively (Figure 2, B). The non-quantitative correspondence between the decrease in the supernatants and the increase in the cell lysates over time was confirmed by the calculation of the mass balance (Figure 2, C), that is the total amount of IBU recovered in all the different compartments at a given time point, compared to the initially added amount. It indicated a "apparent" loss of IBU over time (striped bars in Figure 2, C), which could be attributed to biotransformation processes (slightly lower on $\mathrm{d} 13$ ).

At $100 \mu \mathrm{M}$ IBU (high concentration), the kinetic profile was similar (Figure 2, D and E): the low to high concentration ratio (1/10) was maintained in the IBU amount measured in cell lysates, increasing on both days from 2 min to $1 \mathrm{~h}$. A steady state (1 to $3 \mathrm{~h}$ ) followed and then a decrease to a minimum of $\sim 6$ and $13 \%$ at $24 \mathrm{~h}$ (d0 and d13, respectively) (Figure 2, D).

Figure $2 \mathrm{E}$ illustrates the continuous decrease of IBU in the supernatant showing a steady state from 1 to $3 \mathrm{~h}$ and a drop at $24 \mathrm{~h}$ to $\sim 18$ (day 0 ) and $36 \%$ (day 13) of the initial amount. The relative distribution in the different compartments again showed an apparent 'loss' in mass balance (Figure 2, F).

\subsection{Kinetic profile of IBU in PHH}

When the kinetic profile of IBU was followed in $\mathrm{PHH}$, the different human donors were firstly evaluated individually rather than as biological replicates, due to high intra-individual variability. Although the absolute values were different, representing the expected variability among individuals, analysed donors exhibited a comparable trend: on this basis, distinct donors were handled as biological replicates.

This high variability (translated in high SD bars) was very likely attributed to differences in metabolism, although the hepatic pathology of the donors might also have contributed. In order to characterise the competence of $\mathrm{PHH}$ to metabolise IBU, some CYP specific activities were measured in $\mathrm{PHH}$ from 
495

496

497

498

499

500

501

502

503

504

505

506

507

508

509

510

511

512

513

514

515

516

517

518

519

520

each donor (Table 4). Of particular interest was CYP2C9, which is the main CYP involved in IBU metabolism. PHH from Donor B1032 were expected to show a low level of oxidative IBU metabolism. Indeed, after 3 days of repeated exposure, a high degree of cytotoxicity was observed at both concentrations. As a result, the experiment with $\mathrm{PHH}$ from Donor B1032 was stopped because it did not meet the criteria set in the experimental design, i.e. high concentration corresponding to $\mathrm{TC}_{10}$, thus assuming a nearly constant number of cells throughout the experimental treatment. As a consequence, biokinetic data reported on $\mathrm{d} 13$ included only samples from $\mathrm{PHH}$ from the Donors S1045 and B1050.

The mean IBU concentration at $\mathrm{T}_{0}$ was $97.8 \pm 10.0 \mu \mathrm{M}$ and $803.7 \pm 78.6 \mu \mathrm{M}$ vs the nominal $100 \mu \mathrm{M}$ and $1000 \mu \mathrm{M}$, respectively, with a CV of $2-20 \% \%$ with $\mathrm{N}=20$ (for each concentration).

At $100 \mu \mathrm{M}$ (low concentration) no differences in IBU kinetic profile were evident between d0 and d13. IBU uptake by $\mathrm{PHH}$ was very rapid, reaching maximum values (5\% of the applied concentration) after $2 \mathrm{~min}$ at d0 and after $30 \mathrm{~min}$ at d13 (Figure 3, A). Subsequently, a steady state up to $3 \mathrm{~h}$ was followed by a decrease to a minimum of $~ 1 \%$ at $24 \mathrm{~h}$. IBU content in the PHH supernatant samples showed an almost continuous decrease over time with a less pronounced steady-state at early times. In no case the intracellular amount and the decrease in the supernatant were quantitatively correlated (Figure 3, B). The sum of the amount of IBU found in the cell lysates plus supernatants declined quite rapidly starting from the first time point on d0 (Figure 3, C); on d13 the decreasing rate was slower, but after $24 \mathrm{~h}$ in both cases very low IBU values were attained $(10.2 \pm 4.8 \%$ on d0 and $8.6 \pm 4.3 \%$ on d13). As evidenced by the relative IBU distribution in the different compartments (Figure 3, C), IBU content in the cell lysate never exceeded $5 \%$, the amount measured at the steady state, supporting the occurrence of a very efficient metabolism of the parent compound by $\mathrm{PHH}$.

The kinetic profile in the cell lysate over $24 \mathrm{~h}$ for the $\mathrm{PHH}$ treated with $1000 \mu \mathrm{M}$ (high concentration; Figure 3, D) showed a different pattern; the high/low intracellular concentration ratio was > 10 fold. After a very rapid uptake into the cells, at 2 min the amount of IBU remained at a constant level (around 1-3\%) at d0; although very variable among donors, the trend was similar at d13. In contrast, 
521 the supernatants revealed a slight decrease at earlier time points, (Figure 3, E), then IBU levels were 522 almost constant up to $24 \mathrm{~h}$. On d0 the relative distributions showed a decline in total recovered IBU 523 from cells plus supernatant (Figure 3, F), but never below $50 \%$. After repeated exposures, the $3 \mathrm{~h}$ time 524 point corresponded to very low recovery and nearly no variability between samples and donors, 525 contradicting results obtained both at previous time points as well as at $24 \mathrm{~h}$, when results were 526 consistent with the overall kinetic behaviour were obtained. The data at $3 \mathrm{~h}$ were interpreted as a 527 technical problem, since at $24 \mathrm{~h}$ cell were perfectly viable and CYP2C9 activity was present (data not 528 shown), therefore the low metabolic capacity at $24 \mathrm{~h}$ cannot be attributed to cytotoxicity. Under these 529 conditions, the decrease in IBU mass balance was around $20-30 \%$ with most IBU recovered in the 530 supernatant at $24 \mathrm{~h}$, as shown by its relative distribution (squared bars in Figure 3, F). This suggested 531 a saturation of IBU biotransformation at $1000 \mu \mathrm{M}$, which could be expected at such a high 532 concentration.

533

\section{$534 \quad 3.4 \quad$ Kinetic profile of IBU in HepaRG cells}

535 The actual IBU mean concentration in the media at $t_{0}$ was $7.8 \pm 1.2 \mu \mathrm{M}$ and $85.4 \pm 4.2 \mu \mathrm{M}$ versus the 536 nominal $10 \mu \mathrm{M}$ and $100 \mu \mathrm{M}$, with a CV between 5 and $16 \%$ with $\mathrm{N}=20$ (for each concentration). In HepaRG cells treated with $10 \mu \mathrm{M} I \mathrm{BU}$, the uptake started at $30 \mathrm{~min}$, reaching a plateau after 3-6 $\mathrm{h}$ (Figure 4, A). In the supernatant a continuous decrease in IBU content was measured both on d0 and 539 d13, reaching a similar amount at $24 \mathrm{~h}$ (Figure 4, B). The relative distribution showed a continuous 540 and constant decrease of IBU mass balance in the course of $24 \mathrm{~h}$ both on $\mathrm{d} 0$ and $\mathrm{d} 13$. Although the 541 reduction rate was higher after repeated exposure (Figure 4, C), likely attributable to higher level of $542 \quad$ CYP2C9 on d13.

543 After treatment of HepaRG cells with $100 \mu \mathrm{M}$ IBU (high concentration), the measured kinetic profile 544 was similar: in the cell compartment on d0 and d13 IBU content remained low, under $0.5 \mathrm{nmol} / \mathrm{well}$ 545 (Figure 4, D). A gradual decrease in IBU content was observed in the supernatants on d0 higher on $546 \mathrm{~d} 13$, but never quantitatively related to the increase in intracellular content (Figure 4, E). The total IBU 
recovery showed a continuous decrease over time on both days (Figure 4, F), although significantly

548 lower on d13. This suggests a possible increase in the CYP2C9-related biotransformation capacity of 549 this cell model over time. The IBU amount in the supernatants was 10 fold higher than that measured 550 at $10 \mu \mathrm{M} \mathrm{IBU}$, respecting the high/low concentration ratio, whereas it was $<10$ in cell lysates.

\section{$552 \quad 3.5 \quad$ Pharmacokinetic Modelling}

553 Figure 5 shows the measured and modelled amount of IBU in the medium and cell lysates of PRH 554 cultures over the repeated treatment of 14 days. Since IBU was applied daily, the concentration was 555 reset to nominal medium concentrations every $24 \mathrm{~h}$. It was assumed that IBU content in cell lysate 556 corresponds to intracellular concentrations; the assumption was nevertheless reasonable, since, 557 based on its low lipophilicity ( $\log \mathrm{K}_{\mathrm{ow}}=0.8$ at $\mathrm{pH} 7.4$ ), IBU is unlikely sequestered within membranes.

558 The data were well matched by the model and fairly consistent across replicates. The various curves 559 were very similar, showing that there was reasonable uncertainty in the model predictions (the 560 estimate of residual uncertainty corresponded to a CV of $30 \%)$.

561 A dynamic equilibrium was reached already after the first day. The ratios $Q_{\text {cell }}$ over $Q_{\text {med }}$ were close to 5620.2 , but the total cellular volume was about a 1000th of the medium volume, so the ratio of 563 concentrations was about 200. As a result, cells had a 200 times higher IBU concentration than the medium.

A similar model fitted for $\mathrm{PHH}$ data is shown in Figure 6. The $\mathrm{PHH}$ from Donor $\mathrm{B} 1032$ proved to be 566 very sensitive to IBU toxicity at the applied concentration, thus only data from the first day were obtained. Here, significant inter-individual variability was noted, thus a population approach was used 568 to analyse the data deriving from $\mathrm{PHH}$. The fits were quite good, but uncertainty (reflected by the 569 spreading of the simulated curves) was as expected higher compared to $\mathrm{PRH}$, resulting from 570 underlying measurement errors and modelling approximations (the estimate of residual CV being $57140 \%$ ). In two PHH donors, the intracellular quantity of IBU was noticeably higher than predicted. In the 572 data sets of PHH from Donors S1045 and B1050, a dynamic equilibrium was reached practically on 
$573 \mathrm{~d} 1$, as previously seen in the modelling of the PRH data. The IBU amounts in PHH of the $100 \mu \mathrm{M}$ 574 group were underestimated by the model. This could be due to systematic error in IBU recovery, non575 linearity in cellular uptake of efflux, lower metabolism at IBU low concentration, or some unknown 576 mechanism. More data would be required to identify the actual cause of this observation.

577 The data and model fit for HepaRG cells are given in Figure 7. The applied model layout was similar to 578 that previously described for $\mathrm{PRH}$ and $\mathrm{PHH}$. As for the $\mathrm{PHH}$ data, the three replicates were analysed 579 in a population framework, but reflecting inter-experiment variability instead of inter-individual 580 differences between donors. There was a rather large proportion of non-detectable levels in the low581 dose experiments with substantial uncertainty (residual uncertainty: CV = 45\%). Furthermore, an 582 underestimation of some data points at $10 \mu \mathrm{M}$ concentration in cell lysates was observed as 583 previously observed for the $\mathrm{PHH}$. These results seem however, globally consistent with those of the 584 other two culture systems. For both $\mathrm{PHH}$ and HepaRG cells, the ratios $\mathrm{Q}_{\text {cell }}$ over $\mathrm{Q}_{\text {med }}$ were close to 5850.01 , indicating that those cells had only a 10 times higher IBU concentration compared to the medium 586 - that is much less than in $\mathrm{PRH}$, likely due to more efficient metabolism.

587 The posterior parameter distributions obtained after MCMC sampling for the "average" parameters are 588 summarised in Table 5. They characterise the kinetic behaviour observed an average experiment for $589 \mathrm{PRH}$ or HepaRG cells, or of the cells of an average donor in $\mathrm{PHH}$. Given the dose assayed in the 590 various systems and the cell capabilities, we could estimate a maximum rate of metabolism only in $591 \mathrm{PHH}$. The low-dose metabolic clearances, $\mathrm{V}_{\max } / \mathrm{K}_{\mathrm{m}}$, could be estimated in all systems with very good 592 precision in $\mathrm{PRH}(5 \% \mathrm{CV})$ and less so in $\mathrm{PHH}$ and HepaRG (50\% CV). The PRH have clearly lower 593 clearance rates, which explained the much higher IBU concentrations observed in those cells. 594 Clearance rates were similar for the different human cells, given the significant variability between 595 donors and experiments. In HepaRG cells, metabolic clearance is known to increase with time, and 596 we estimated (slope parameter $\alpha$ ) that it was about $60 \%$ higher after 14 days compared to the start 597 (Table 5). 


\section{Discussion}

600 To overcome the imbalance between rising costs and declining approvals of new drugs, the 601 pharmaceutical industry is under pressure to improve the effectiveness of the drug development 602 process, and reduce the current high attrition rates. Toxicity testing is crucial, but represents a time603 and resource-consuming step; in addition human ADRs to the liver are often difficult to predict with 604 existing animal models. These considerations, besides the ethical considerations related to the use of 605 laboratory animals, promote the development of more suitable in vitro methods. This paper addresses 606 the importance of measuring in vitro biokinetics, generally not taken into account even in well607 established experimental in vitro models, in order to improve the predictability of in vitro data, and to 608 be used as input in PBPK models (Coecke et al., 2013). We used three different hepatic cellular 609 systems, with IBU as a model compound.

610 IBU is a widely used as analgesic/antipyretic agent, available by prescription and over-the-counter; at 611 therapeutic doses it is reported, although rarely, to induce ADRs to the liver (Bennett et al., 2009; 612 Rodríguez-González et al., 2002; Laurent et al., 2000). Among them, sub-acute hepatic failure, 613 hepatitis $C$ cases and significant increase in transaminases (O'Connor et al., 2003). In humans, the 614 first step in IBU metabolism is catalysed by CYP2C9 and to a lower extent by 2C8 (Chang et al., 615 2008), to form 2-Hydroxy-IBU and Carboxy-IBU, as major detoxification metabolites (Hamman et al., 616 1997). The rat CYP2c6 and 2c11, orthologs of human CYP2C9 (Vecera et al., 2011), are thought to 617 be involved in these oxidative reactions (Hu et al., 2011; Kapil et al., 2004). IBU and its oxidative non618 toxic metabolites are conjugated with glucuronic acid by different UGTs in vitro in rat or human 619 hepatocytes (Dong and Smith, 2009) and in vivo (Spraul et al., 1992) and then excreted, mainly in 620 urine.

621 As the first step we checked factors possibly affecting the bioavailability of IBU under the experimental 622 conditions used, and showed that IBU was readily soluble and chemically stable, neither cross623 contamination among wells nor adsorption to plastic devices occurred. The use of FBS or albumin in 624 the medium was reduced to a minimum, i.e. not affecting IBU recovery or total bioavailability. 
625 Furthermore, no IBU was physically sequestered into the Geltrex ${ }^{\mathrm{TM}}$ used in PHH SW culture. By 626 contrast, we found a time- and concentration-dependent amount of IBU in collagen I used in PRH 627 cultures. This finding was relevant because physically sequestered IBU could be assumed as 628 intracellular content, and erroneously interpreted as bioaccumulation.

629 The study design was similar to that of the in vivo kinetic testing (OECD Test Guideline 417). The 630 comparison of kinetic behaviour obtained between single and repeated treatments allowed the study 631 of inhibition, saturation or induction of cellular influx/efflux, metabolism and bioaccumulation 632 processes.

633 The used $100 \mu \mathrm{M}$ IBU corresponds to $20.6 \mu \mathrm{g} / \mathrm{mL}$, which approximates the recently reported human 634 peak plasma concentration $\left(C_{\max }=22.6 \pm 5.6 \mu \mathrm{g} / \mathrm{mL}\right)$ measured upon oral intake of $400 \mathrm{mg}$ IBU 635 (Vilenchik et al., 2012) in the low range of therapeutic doses. Hence, the cross-model comparison of 636 the three hepatic systems was conducted at $100 \mu \mathrm{M}$ IBU.

637 The obtained modelled results showed a coherent picture for IBU in vitro biokinetics across the three 638 models: (i) IBU quickly entered cells; (ii) after multiple exposures a dynamic equilibrium was reached 639 within one or two days; (iii) the decrease in the medium was not quantitatively related to the increase 640 in the cell lysate fractions. All three models showed a significant capacity in metabolising IBU; 641 therefore, cells removed (by biotransformation) the parent compound in $24 \mathrm{~h}$, resulting in no 642 bioaccumulation after daily treatment for 14 days This is in line with information from in vivo 643 pharmacokinetic data in humans showing that $60 \%$ of a given dose was excreted within the first $24 \mathrm{~h}$ 644 (Adams et al., 1969). Although the experimental data were available only on d0 and d13, modelling 645 allowed the prediction of the daily kinetic behaviour along the treatment period.

646 The uptake of IBU was likely due to passive transport through the cell membrane, being very rapid 647 and not saturable: and assumed to be a "first order" kinetic process. Our assumption was supported 648 by experiments conducted on Caco2 cells indicating a passive transport (data not shown) and by data 649 showing that in rats IBU is an Oatp1a1 inhibitor (Zhang et al., 2013) and in human cells IBU inhibits 650 OATP1B1 or OATP1B3, without being a substrate (Kindal et al., 2011). The modelling showed that 
cellular uptake was much faster compared to its output; since, once entered, the drug was rapidly metabolised, the efflux back in the medium compartment, if any, was considered negligible. An initial slower intracellular uptake characterised HepaRG cells (paralleled by a slower decrease of IBU content in the medium fraction, Figure $8 \mathrm{~B}$ at $\mathrm{d} 0$ ). It could be attributed to the presence of $2 \%$ FBS in the medium binding IBU. However, considering protein binding as a fast process, despite the cell uptake rate was initially slower, the total amount of IBU entering the cells within $24 \mathrm{~h}$ was the same (>90\% IBU "lost" in the mass balance estimate). The consequence could be a slight overestimation in the HepaRG clearance.

After single exposure, the steady state was reached rapidly in $\mathrm{PHH}(2-30 \mathrm{~min})>\mathrm{PRH}(1-3 \mathrm{~h})>$ HepaRG (3-6h). The higher intracellular concentration detected in $\mathrm{PRH}$ than in human derived cells (Figure $8 \mathrm{~A}, \mathrm{C}$ ) at the steady state could be due to the different metabolic clearance rates, which in the rat model are one order of magnitude lower compared to the human-derived cells (Table 5). The difference in metabolic clearance was shown also in vivo (Adams et al., 1969), with a more efficient IBU metabolism in humans compared to the rat.

The HepaRG cells showed lower IBU concentrations in the cell lysates than $\mathrm{PHH}$, particularly after repeated treatment. This could be due, at least partially, to the $60 \%$ increase over time of IBU metabolic clearance in HepaRG cells (Table 5) which was not a compound-specific effect. Indeed, higher levels of CYP2C9 activity at 14 days of culture have been reported (Anthérieu et al., 2010) as well as for other CYPs (Jossé et al., 2008). In addition, transcriptomics measurements indicated no significant increase in CYP2C9 mRNA indicative of induction by IBU treatment, although few genes involved in drug metabolism were increased in control cells on d13 (data not shown). The absence of induction throughout the course of repeated exposure in the three models was in accordance with in vivo data (Mills et al., 1973).

The efficiency of IBU metabolism seemed to be a strong determinant for its toxicity in hepatocytes. Here, $\mathrm{PRH}$, with a slower metabolic clearance, showed a higher toxicity compared to $\mathrm{PHH}$ although, due to the high inter-individual variability in $\mathrm{PHH}$, the obtained $\mathrm{TC}_{10}$ cannot be considered as 
677 representative of the average human population. Indeed, $\mathrm{PHH}$ from Donor B1032, characterised by 678 low CYP2C9 activity and thus, by a low IBU detoxification, experienced a high cytotoxicity, leading to 679 experiment termination after 3 days. It is unclear why $\mathrm{TC}_{10}$ in $\mathrm{HepaRG}$ was lower than $\mathrm{PHH}$ and 680 similar to $\mathrm{PRH}$, although having a much higher metabolic clearance. A possible explanation, beside 681 the lower number of cells (50\% of the population is made of biliary cells) is a different balance 682 between phase-1 and phase-2 metabolism in the three models. Although not measured and modelled 683 in this work, glucuronidation has been also shown to play a role in the metabolic disposition of most 684 'profens' Since species differences have been described in glucuronidation rates in liver microsomes 685 (rate ranking: man, monkey, dog, rabbit and rat) (Magdalou et al., 1990), phase 2 metabolism may 686 contribute to differences in the total biotransformation as well as to IBU-induced toxicity among 687 species and between the human-derived models. Indeed, 'profen'-acyl glucuronides have been shown 688 to form covalent protein adducts in rat hepatocytes (Dong and Smith, 2009), contributing to hepatic 689 toxicity. Although IBU is glucuronidated less efficiently than other compounds of the same family 690 (Magdalou et al., 1990) and IBU-acyl glucuronides are considered less reactive among those formed 691 with other 'profens' (Castillo et al., 1995), their higher formation in the PHH from Donor B1032, due to 692 the scant CYP2C9 activity, may be responsible for the pronounced toxicity.

693 Here, the disappearance of the parent compound over time was used as a measure for metabolic 694 clearance. The detection of the different metabolites, including glucuronides, would have delivered 695 valuable additional information whether DMEs are differentially active in the three in vitro systems, 696 accounting for the observed differences. The use of DME-phenotyped $\mathrm{PHH}$ could further help in the 697 full understanding of metabolism-related IBU toxicity. Overall, the observed metabolism-dependent 698 toxicity could be a hint to the rather idiosyncratic nature of IBU-induced liver injury in patients (Bennett 699 et al., 2009; Rodríguez-González et al., 2002; Laurent et al., 2000).

700 The importance of the intracellular concentration for concentration-response extrapolations was 701 comprehensively described by Groothuis et al. (2013). Here we provide evidence that the use of 702 nominal concentrations would have resulted in an overestimation of the actual treatment (up to 20\%). 
703 More importantly, the content in the cell lysates over time appeared to be different in the three hepatic 704 models tested. The disappearance of the test item in the culture medium which was, from a technical 705 point of view, less demanding than testing the cell lysate fraction, showed no major differences in the 706 three hepatocyte models after repeated treatment. Hence, monitoring the biokinetic profile in this 707 single compartment did not allow the drawing of any clear conclusions. Consequently, the 708 measurement of the compound in the cell lysates and the calculation of the relative distributions using 709 mass balance values, were crucial parameters to be monitored.

710 Overall, in terms of species-differences, our data reflected the in vivo situation. Here, consideration of 711 dose-normalised pharmacokinetic parameters such as $\mathrm{C}_{\max }$ (rat $<$ human), $\mathrm{T}_{\max }$ (rat $<$ human) and $\mathrm{t}_{1 / 2}$ 712 (rat $\sim$ human) revealed that at $100 \mu \mathrm{M}$ IBU was metabolised as in vivo more efficiently in humans 713 compared to rats (Hu et al.,2011; Kapil et al., 2004; Teng et al., 2003; Adeyeye et al., 1996). Although $714 \mathrm{PRH}$ appeared to give reproducible results, as expected by the species-specificity, IBU intracellular 715 concentration in $\mathrm{PRH}$ did not correspond to IBU intracellular concentrations found in human cells 716 under similar exposure conditions, suggesting a poor predictivity from this species. A high variability 717 was shown by $\mathrm{PHH}$ from the different donors, although modelling made it possible to account for (and 718 in reduce) variability between donors. The residual uncertainty (Table 5 and in model prediction 719 Figures) was overall about $10 \%$. The number of donors tested was limited, but the use of an appropriately higher number of donors could provide an estimate of human variability, which may be considered an advantage, representing the inter-individual differences observed clinically. HepaRG cells gave very reproducible data and although a large population ( 50\%) of non-metabolising biliary cells is present, they did not bioaccumulate IBU. This was in line with previous data showing that 724 cryopreserved HepaRG cells are a valuable tool for kinetic prediction of CYP substrates (Zanelli et al., 725 2012).

726

\section{Conclusion}


728 The consideration of the biokinetic profiles could help explaining specific observations, i.e. 729 transcriptome, proteome and enzyme induction/inhibition, and support a more holistic biological 730 interpretation. Biokinetics is the link between the applied dose and the observed effects. Modelling 731 these effects taking into account the time course of concentrations is at the root of time-based 732 simulations of effects, i.e. pharmacokinetic/pharmacodynamic (PKPD) modelling, allowing one to 733 make predictions from in vitro to in vivo effects. Finally, the transformation of an in vitro NOAEC to a 734 relevant in vivo NOAEL would greatly benefit drug discovery and reduce the chance of hepatotoxic 735 compounds making it through to clinical trials or on to the market.

736

\section{Acknowledgements}

738 The authors would like to thank the European Commission Seventh Framework Programme (Project 739 reference: 202222) for financial support. The administrative and organisation skills of Hannelore Popa740 Henning are also much appreciated. 
743

744

745

746

747

748

749

750

751

752

753

754

755

756

757

758

759

760

761

762

763

764

765

766

767

768

769

770

771

772

773

774

775

776

777

778

779

780

781

782

783

784

785

786

787

788

789

790

791

792

Adams SS, Bough RG, Cliffe EE, Lessel B, Mills RF (1969) Absorption, distribution and toxicity of ibuprofen. Toxicol Appl Pharmacol 15: 310-30.

Adeyeye CM, Bricker JD, Vilivalam VD, Smith WI (1996) Acute gastrointestinal toxic effects of suspensions of unencapsulated and encapsulated ibuprofen in rats. Pharm Res 13: 784-93.

Adler S, Basketter D, Creton S, Pelkonen O, van Benthem J, Zuang V, Andersen KE, Angers-Loustau A, Aptula A, Bal-Price A, Benfenati E, Bernauer U, Bessems J, Bois FY, Boobis A, Brandon E, Bremer S, Broschard T, Casati S, Coecke S, Corvi R, Cronin M, Daston G, Dekant W, Felter S, Grignard E, Gundert-Remy U, Heinonen T, Kimber I, Kleinjans J, Komulainen H, Kreiling R, Kreysa J, Leite SB, Loizou G, Maxwell G, Mazzatorta P, Munn S, Pfuhler S, Phrakonkham P, Piersma A, Poth A, Prieto P, Repetto G, Rogiers V, Schoeters G, Schwarz M, Serafimova R, Taehti H, Testai E, van Delft J, van Loveren H, Vinken M, Worth A, Zaldivar JM (2011) Alternative (non-animal) methods for cosmetics testing: current status and future prospects-2010. Arch Toxicol 85: 367-485.

Alexandre E, Baze A, Parmentier C, Desbans C, Pekthong D, Gerin B, Wack C, Bachellier P, Heyd B, Weber JC, Richert $L$ (2012) Plateable cryopreserved human hepatocytes for the assessment of cytochrome P450 inducibility: experimental condition-related variables affecting their response to inducers. Xenobiotica 42: 968-79.

Aninat C, Piton A, Glaise D, Le Charpentier T, Langouët S, Morel F, Guguen-Guillouzo C, Guillouzo A (2006) Expression of cytochromes P450, conjugating enzymes and nuclear receptors in human hepatoma HepaRG cells. Drug Metab Dispos 34: 75-83.

Anthérieu S, Chesné C, Li R, Camus S, Lahoz A, Picazo L, Turpeinen M, Tolonen A, Uusitalo J, Guguen-Guillouzo C, Guillouzo A (2010) Stable expression, activity, and inducibility of cytochromes P450 in differentiated HepaRG cells. Drug Metab Dispos. 38: 516-25.

Anthérieu S, Chesné C, Li R, Guguen-Guillouzo C, Guillouzo A (2012) Optimization of the HepaRG cell model for drug metabolism and toxicity studies. Toxicol In vitro 26: 1278-85.

Armitage JM, Wania F, and Arnot JA (2014) Application of mass balance models and the chemical activity concept to facilitate the use of in vitro toxicity data for Risk Assessment. Environ. Sci. Technol. 48: 9770-9779

Bauer RJ, Guzy S, Ng C (2007) A survey of population analysis methods and software for complex pharmacokinetic and pharmacodynamic models with examples. AAPS J9: E60-83.

Bennett WE Jr, Turmelle YP, Shepherd RW (2009) Ibuprofen-induced liver injury in an adolescent athlete. Clin Pediatr (Phila) 48: 84-6.

Bois FY (2009) GNU MCSim: Bayesian statistical inference for SBML-coded systems biology models. Bioinformatics 25: 1453-4.

Bois FY, Jamei M, Clewell HJ (2010) PBPK modelling of inter-individual variability in the pharmacokinetics of environmental chemicals. Toxicology 278: 256-67.

Castillo M, Lam YW, Dooley MA, Stahl E, Smith PC. (1995) Disposition and covalent binding of ibuprofen and its acyl glucuronide in the elderly. Clin Pharmacol Ther. 57:636-44.

Cerec V, Glaise D, Garnier D, Morosan S, Turlin B, Drenou B, Gripon P, Kremsdorf D, GuguenGuillouzo C, Corlu A (2007) Transdifferentiation of hepatocyte-like cells from the human hepatoma HepaRG cell line through bipotent progenitor. Hepatology 45: 957-67.

Chang SY, Li W, Traeger SC, Wang B, Cui D, Zhang H, Wen B, Rodrigues AD (2008) Confirmation that cytochrome P450 2C8 (CYP2C8) plays a minor role in (S)-(+)- and (R)-(-)-ibuprofen hydroxylation in vitro. Drug Metab Dispos 36: 2513-22.

Coecke S, Pelkonen O, Leite SB, Bernauer U, Bessems JG, Bois FY, Gundert-Remy U, Loizou G, Testai E, Zaldívar JM (2013) Toxicokinetics as a key to the integrated toxicity risk assessment based primarily on non-animal approaches. Toxicol In vitro 27: 1570-7.

Dong JQ, and Smith PC (2009) Glucuronidation and covalent protein binding of benoxaprofen and flunoxaprofen in sandwich-cultured rat and human hepatocytes. Drug Metab Dispos 37: 23142322. 
Gelman A and Rubin DB (1992) Inference from Iterative Simulation Using Multiple Sequences. Statistical Sciences 7: 457-511.

Gelman A, Bois F, Jiang J (1996) Physiological pharmacokinetic analysis using population modeling and informative prior distributions. Journal of the American Statistical Association 91: 1400-1412.

Gripon P, Rumin S, Urban S, Le Seyec J, Glaise D, Cannie I, Guyomard C, Lucas J, Trepo C, Guguen-Guillouzo C (2002) Infection of a human hepatoma cell line by hepatitis B virus. Proc Natl Acad Sci U S A99: 15655-60.

Groothuis FA, Heringa MB, Nicol B, Hermens JL, Blaauboer BJ, Kramer NI (2013) Dose metric considerations in in vitro assays to improve quantitative in vitro-in vivo dose extrapolations. Toxicology. In press. doi: 10.1016/j.tox.2013.08.012.

Guillouzo A (1998) Liver cell models in in vitro toxicology. Environ Health Perspect106: 511-32.

Guelden M, Moerchel S, Seibert H (2001) Factors influencing nominal effective concentrations of chemical compounds in vitro: cell concentration. Toxicol In vitro 15: 233-43.

Guelden M, Jess A, Kammann J, Maser E, Seibert H (2010) Cytotoxic potency of H2O2 in cell cultures: impact of cell concentration and exposure time. Free Radic Biol Med 49: 1298-305.

Hamman MA, Thompson GA, Hall SD (1997) Regioselective and stereoselective metabolism of ibuprofen by human cytochrome P450 2C. Biochem Pharmacol 54: 33-41.

Hassan AS, Sapin A, Ubrich N, Maincent P, Bolzan C, Leroy P (2008) Simple and sensitive HPLC method with fluorescence detection for the measurement of ibuprofen in rat plasma: application to a long-lasting dosage form. Drug Dev Ind Pharm 34: 1064-70.

Hewitt NJ, Gomez-Lechon MJ, Houston JB, Hallifax D, Brown HS, Maurel P, Kenna JG, Gustavsson L, Lohmann C, Skonberg C, Guillouzo A, Tuschl G, Li AP, LeCluyse E, Groothuis GM, and Hengstler JG (2007) Primary hepatocytes: current understanding of the regulation of metabolic enzymes and transporter proteins, and pharmaceutical practice for the use of hepatocytes in metabolism, enzyme induction, transporter, clearance, and hepatotoxicity studies. Drug Metab Rev 39: 159-234.

Hu L, Yang J, Liu W, Li L (2011) Preparation and evaluation of ibuprofen-loaded microemulsion for improvement of oral bioavailability. Drug Deliv 18: 90-5.

Jossé R, Aninat C, Glaise D, Dumont J, Fessard V, Morel F, Poul JM, Guguen-Guillouzo C, Guillouzo A (2008) Long-term functional stability of human HepaRG hepatocytes and use for chronic toxicity and genotoxicity studies. Drug Metab Dispos 36: 1111-8.

Kanebratt KP, Andersson TB (2008) Evaluation of HepaRG cells as an in vitro model for human drug metabolism studies.Drug Metab Dispos 36: 1444-52.

Kapil R, Nolting A, Roy P, Fiske W, Benedek I, Abramowitz W (2004) Pharmacokinetic properties of combination oxycodone plus racemic ibuprofen: two randomized, open-label, crossover studies in healthy adult volunteers. Clin Ther 26: 2015-25.

Kindla J, Müller F, Mieth M, Fromm M.F., and Koenig J (2011) Influence of non-steroidal antiinflammatory drugs on organic anion transporting polypeptide OATP1B1- and OATP1B3mediated drug transport. Drug Metab Dispos 39:1047-1053.

Kola I, Landis J (2004) Can the pharmaceutical industry reduce attrition rates? Nat Rev Drug Discov 3: 711-5.

Kramer NI, Krismartina M, Rico-Rico A, Blaauboer BJ, Hermens JLM (2012).Quantifying processes determining the free concentration of phenanthrene in basal cytotoxicity assays. Chem. Res. Toxicol. 25: 436-445.

Laurent S, Rahier J, Geubel AP, Lerut J, Horsmans Y (2000) Subfulminant hepatitis requiring liver transplantation following ibuprofen overdose. Liver 20: 93-4.

Lecluyse EL and Alexandre E (2010) Isolation and culture of primary hepatocytes from resected human liver tissue. Methods Mol Biol 640: 57-82.

Lodish H, Berk A, Matsudaira P, Kaiser CA, Krieger M, Scott MP, Zipursky L, and Darnell J (2000) Molecular Cell Biology, fifth ed. Freeman, New York.

Magdalou J, Chajes V, Lafaurie C and Siest G (1990) Glucuronidation of 2-arylpropionic acids pirprofen, flurbiprofen, and ibuprofen by liver microsomes.Drug Metab Dispos 18: 692-697. 
845

846

847

848

849

850

851

852

853

854

855

856

857

858

859

860

861

862

863

864

865

866

867

868

869

870

871

872

873

874

875

876

877

878

879

880

881

882

883

884

885

886

887

888

889

890

891

892

893

894

Mills RF, Adams SS, Cliffe EE, Dickinson W, Nicholson JS (1973) The metabolism of ibuprofen. Xenobiotica 3: 589-98.

O'Connor N, Dargan PI, Jones AL (2003) Hepatocellular damage from non-steroidal anti-inflammatory drugs. QJM 96: 787-91.

Parmentier C, Truisi GL, Moenks K, Stanzel S, Lukas A, Kopp-Schneider A, Alexandre E, Hewitt PG, Mueller SO, Richert L (2013) Transcriptomic hepatotoxicity signature of chlorpromazine after short- and long-term exposure in primary human sandwich cultures. Drug Metab Dispos 41: 183542.

Pomponio G, Savary C, Parmentier C, Bois F, Guillozo A, Romanelli L, Richert L, Di Consiglio E, Testai E. (2014) In vitro kinetics of amiodarone and its major metabolite in two human liver cell models after acute and repeated treatments. Toxicol. in vitro Accepted for publication.

Rainsford KD (2009) Ibuprofen: pharmacology, efficacy and safety. Inflammopharmacology 17: 275342.

Rodríguez-González FJ, Montero JL, Puente J, Fraga E, Costán G, Barrera P, Muntané J, De la Mata M, Zambrana JL (2002) Orthotopic liver transplantation after subacute liver failure induced by therapeutic doses of ibuprofen. Am J Gastroenterol 97: 2476-7.

Seglen PO (1976) Preparation of isolated rat liver cells. Methods Cell Biol 13: 29-83.

Seibert H, Moerchel S, Guelden M (2002) Factors influencing nominal effective concentrations of chemical compounds in vitro: medium protein concentration. Toxicol In vitro 16: 289-97.

Shanks N, Greek R, Greek J (2009) Are animal models predictive for humans? Philos Ethics Humanit Med 4: 2 .

Spraul M, Hofmann M, Dvortsak P, Nicholson JK, Wilson ID (1992) Liquid chromatography coupled with high-field proton NMR for profiling human urine for endogenous compounds and drug metabolites. J Pharm Biomed Anal 10: 601-5.

Teng XW, Wang SW, Davies NM (2003) Stereospecific high-performance liquid chromatographic analysis of ibuprofen in rat serum. J Chromatogr B Analyt Technol Biomed Life Sci 796: 225-31.

Tirelli V, Catone T, Turco L, Di Consiglio E, Testai E, De Angelis I (2007) Effects of the pesticide clorpyrifos on an in vitro model of intestinal barrier. Toxicol In vitro 21: 308-13.

Tuschl G, Lauer B, Mueller SO (2008) Primary hepatocytes as a model to analyze species-specific toxicity and drug metabolism. Expert Opin Drug Metab Toxicol 4: 855-70.

Tuschl G, Hrach J, Walter Y, Hewitt PG, Mueller SO (2009) Serum-free collagen sandwich cultures of adult rat hepatocytes maintain liver-like properties long term: a valuable model for in vitro toxicity and drug-drug interaction studies. Chem Biol Interact 181: 124-37.

Večeřa R, Zachařová A, Orolin J, Strojil J, Skottová N, Anzenbacher P (2011) Fenofibrate-induced decrease of expression of CYP2C11 and CYP2C6 in rat. Biopharm Drug Dispos 32: 482-7.

Vilenchik R, Berkovitch M, Jossifoff A, Ben-Zvi Z, Kozer E (2012) Oral versus rectal ibuprofen in healthy volunteers. J Popul Ther Clin Pharmacol 19: e179-86.

Wilmes A, Limonciel A, Aschauer L, Moenks K, Bielow C, Leonard MO, Hamon J, Carpi D, Ruzek S, Handler A, Schmal O, Herrgen K, Bellwon P, Burek C, Truisi GL, Hewitt P, Di Consiglio E, Testai E, Blaauboer BJ, Guillou C, Huber CG, Lukas A, Pfaller W, Mueller SO, Bois FY, Dekant W, Jennings P (2013) Application of integrated transcriptomic, proteomic and metabolomic profiling for the delineation of mechanisms of drug induced cell stress. J Proteomics 79: 180-94.

Zanelli U, Caradonna NP, Hallifax D, Turlizzi E, Houston JB (2012) Comparison of cryopreserved HepaRG cells with cryopreserved human hepatocytes for prediction of clearance for 26 drugs. Drug Metab Dispos 40: 104-10.

Zhang A, Wang C, Liu Q, Meng Q, Peng J, Sun H, Ma X, Huo X, and Liu K (2013) Involvement of organic anion-transporting polypeptides in thehepatic uptake of dioscin in rats and humans Drug Metab Dispos 41:994-1003. 
Figure Legends

896 Figure 1. Schematic representation of the three-compartment model used for ibuprofen in vitro 897 pharmacokinetics.

898

899 Figure 2. Kinetic profile of ibuprofen (IBU) (nmol/well) in primary rat hepatocytes $(P R H)(A, D)$ and 900 culture supernatants $(B, E)$ after single (day $0(d 0)$ - dashed line) and repeated (day 13 (d13) - solid 901 line) treatment with $10 \mu \mathrm{M}$ IBU $(\mathrm{A}, \mathrm{B})$ or $100 \mu \mathrm{M}$ IBU (D, E). Relative distribution (\%) of IBU in the 902 different analysed PRH fractions at the indicated time points for $\mathrm{d} 0$ and $\mathrm{d} 13$, supernatant (squared) 903 and cell lysate (blank) as well as the apparent loss (striped) for the low concentration (10 $\mu \mathrm{M}, \mathrm{C})$ and 904 high concentration $(100 \mu \mathrm{M}, \mathrm{F})$. Values are given as mean of three biological replicates +/- SD 905 (standard deviation); each sample was run in two technical replicates. The significance of the results 906 was analysed by the Student t test $(p<0.05)$ : the letter a indicates statistically significant differences 907 between each data point and the first time point; the letter $\underline{b}$ indicates statistically significant 908 differences between each data point and the immediately precedent time point.

909

910 Figure 3. Kinetic profile of ibuprofen (IBU) (nmol/well) in primary human hepatocytes (PHH) (A, D) and 911 culture supernatants (B, E) after single (day $0(\mathrm{~d} 0)$ - dashed line) and repeated (day 13 (d13) - solid 912 line) treatment with $100 \mu \mathrm{M}$ IBU (A, B) or $1000 \mu \mathrm{M}$ IBU (D, E). Relative distribution (\%) of IBU in the 913 different analysed $\mathrm{PHH}$ fractions at the indicated time points for $\mathrm{d} 0$ and $\mathrm{d} 13$, supernatant (squared) 914 and cell lysate (blank) as well as the apparent loss (striped) for the low concentration (100 $\mu \mathrm{M}, \mathrm{C})$ and 915 high concentration $(1000 \mu \mathrm{M}, \mathrm{F})$. As the $\mathrm{PHH}$ from Donor B1032 evidenced a high cytotoxicity after 3 916 days of treatment with IBU, values are given as mean of two (d13) or three (d0) biological replicates $917+$ +- SD; each sample was run in two technical replicates.

918

919 Figure 4. Kinetic profile of ibuprofen (IBU) (nmol/well) in HepaRG cells (A, D) and culture supernatants $920(\mathrm{~B}, \mathrm{E})$ after single (day $0(\mathrm{~d} 0)$ - dashed line) and repeated (day $13(\mathrm{~d} 13)$ - solid line) treatment with 
$92110 \mu \mathrm{M}$ IBU $(\mathrm{A}, \mathrm{B})$ or $100 \mu \mathrm{M}$ IBU $(\mathrm{D}, \mathrm{E})$. Relative distribution (\%) of IBU in the different analysed 922 HepaRG cell fractions at the indicated time points for d0 and d13, supernatant (squared) and cell 923 lysate (blank) as well as the apparent loss (striped) for the low concentration (10 $\mu \mathrm{M}, \mathrm{C})$ and high 924 concentration $(100 \mu \mathrm{M}, \mathrm{F})$. Values are given as mean of three biological replicates +/- SD; each 925 sample was run in two technical replicates. The significance of results was analysed by the Student $t$ 926 test $(p<0.05)$ : the letter a indicates statistically significant differences between each data point and the 927 first time point; the letter $\underline{b}$ indicates statistically significant differences between each data point and 928 the immediately precedent time point.

929

930 Figure 5. Amount of ibuprofen (IBU) in nmol, measured in the medium (triangles) and cell lysates 931 (circles) of primary rat hepatocytes (PRH) cultures, superimposed with the best (maximum posterior) 932 fit of the three-compartment pharmacokinetic model (thick black line) and a set of predictions 933 generated from random set of posterior parameter values (thin black lines). IBU was applied daily at 934 either high (100 $\mu \mathrm{M}$ corresponding to $150-200 \mathrm{nmol}$ per day; top row $\mathrm{A})$ or low concentration $(10 \mu \mathrm{M}$ 935 corresponding to $15-20 \mathrm{nmol}$ per day; bottom row B). Three biological replicates were analysed (in 936 column, 1-3).

937

938 Figure 6. Amount of ibuprofen (IBU) in nmol measured in the medium (triangles) and cell lysates 939 (circles) of primary human hepatocytes $(\mathrm{PHH})$ cultures, superimposed with the best (maximum 940 posterior) fit of the three-compartment pharmacokinetic model (thick black line) and a set of 941 predictions generated from random set of posterior parameter values (thin black lines). IBU was 942 applied daily at either high $(1000 \mu \mathrm{M}$ corresponding to $1.5-2 \mu \mathrm{mol}$ per day; top row A) or low 943 concentration (100 $\mu \mathrm{M}$ corresponding to $150-200 \mathrm{nmol}$ per day; bottom row $\mathrm{B}$ ). Three donors were 944 analysed (in column, 1-3) in population pharmacokinetic framework. Experiment with PHH from Donor 945 B1032 was stopped, due to the toxicity of IBU to those cells. 
947 Figure 7. Amount of ibuprofen (IBU) in nmol measured in the medium (triangles) and cell lysates 948 (circles) of HepaRG cultures, superimposed with the best (maximum posterior) fit of the three949 compartment pharmacokinetic model (thick black line) and a set of predictions generated from random 950 set of posterior parameter values (thin black lines). IBU was applied daily at either high (150-200nmol 951 per day; top row A) or low concentration (10-20nmol per day; bottom row B). Three replicate 952 experiments were analysed (in column, 1-3) in population pharmacokinetic framework.

953

954 Figure 8. Cross model comparison between primary rat hepatocytes $(\mathrm{PRH})$ (dashed line), primary 955 human hepatocytes $(\mathrm{PHH})$ (squares, solid line) and HepaRG cells (triangles, solid line): Biokinetic 956 profile of ibuprofen (IBU) (nmol/well) in cell lysates (A, C) and culture supernatants (B, D) after single 957 (day 0 (d0) - upper panel: A, B) and repeated (day 13 (d13) - lower panel: C, D) treatment with 100 $958 \mu \mathrm{M}$ IBU. The five time point correspond to $2 \mathrm{~min}, 30 \mathrm{~min}, 1 \mathrm{~h}, 3 \mathrm{~h}$ and $24 \mathrm{~h}$ for $\mathrm{PRH}$ and $\mathrm{PHH}$, and 30 $959 \min , 3 \mathrm{~h}, 6 \mathrm{~h}, 12 \mathrm{~h}$ and $24 \mathrm{~h}$ for HepaRG cells. Values are given as mean of three biological replicates $960+$ + SD; each sample was run in two technical replicates. 
962 Tables

963 Table 1. Detailed information on the donors of liver resections utilised within this study.

\begin{tabular}{|c|c|c|c|c|}
\hline Donor & Sex & Age & Pathology & Medication \\
\hline S0302V ${ }^{\mathrm{a}}$ & Male & 61 & $\begin{array}{l}\text { Sigmoid } \\
\text { adenocarcinoma }\end{array}$ & $\begin{array}{l}\text { Lypanthyl, Stagid, } \\
\text { Cotareg, Insulin, Sotalex }\end{array}$ \\
\hline B1032 & Male & 42 & $\begin{array}{l}\text { Echinococcosis } \\
\text { alveolaris }\end{array}$ & none \\
\hline S1045 & Male & 75 & Hepatic tumor & $\begin{array}{l}\text { Atenolol, Kardegic, } \\
\text { Ramipril, Inspra, Rasilez }\end{array}$ \\
\hline B1050 & Male & 63 & Hydatid Cyst & none \\
\hline
\end{tabular}

964

$965{ }^{a}$ This sample was used only for a preliminary assessment of IBU cytotoxicity. It was not further used 966 for the kinetic experiments, 
968 Table 2. Ibuprofen (IBU) concentrations applied to primary rat hepatocytes (PRH) cultures in different 969 conditions for determination of the concentration that causes $10 \%$ cytotoxicity.

\begin{tabular}{|c|c|c|c|c|c|c|}
\hline Culture condition & & & [IBU] & & & \\
\hline 96-well (ML - 24h) & 500 & 1000 & 1500 & 2000 & 3500 & 5000 \\
\hline 24-well (SW - 1, 3, 14d) & 1 & 10 & 100 & 500 & 1000 & 2000 \\
\hline 6-well (SW - 14d) & 10 & 500 & 1000 & & & \\
\hline
\end{tabular}

970

971 
972 Table 3. IBU sequestered by collagen I used for primary rat hepatocytes $(\mathrm{PRH})$ long-term cultures.

\begin{tabular}{|c|c|c|c|}
\hline & & \multicolumn{2}{|c|}{ IBU in \% } \\
\hline \multirow{2}{*}{$\mathrm{d} 0$} & $2 \min$ & $\begin{array}{c}1.6 \pm 1.3 \\
(101.3 \pm 1.3)\end{array}$ & $\begin{array}{c}3.4 \pm 0.4 \\
(98.2 \pm 0.3)\end{array}$ \\
\hline & $24 \mathrm{~h}$ & $\begin{array}{c}13.6 \pm 2.7 \\
(97.6 \pm 5.8)\end{array}$ & $\begin{array}{c}15.1 \pm 0.9 \\
(103.4 \pm 2.2)\end{array}$ \\
\hline \multirow{3}{*}{ d13 } & $2 \min$ & $\begin{array}{l}29.3 \pm 0.6 \\
(94.3 \pm 3.1)\end{array}$ & $\begin{array}{c}28.5 \pm 1.3 \\
(99.8 \pm 5.6)\end{array}$ \\
\hline & $24 \mathrm{~h}$ & $\begin{array}{c}31.4 \pm 3.0 \\
(104.3 \pm 0.9)\end{array}$ & $\begin{array}{c}26.4 \pm 1.7 \\
(106.3 \pm 1.7)\end{array}$ \\
\hline & $\begin{array}{l}\text { Nominal } \\
\text { concentration }\end{array}$ & IBU 10 $\mu \mathrm{M}$ & IBU $100 \mu M$ \\
\hline
\end{tabular}

973

974 Values are given in per cent of IBU detected in collagen I, compared with IBU detected in cell media at

$975 \mathrm{~T}_{0}$. Figures in parentheses are the total IBU recovery (media + collagen I). Results are expressed as 976 mean \pm standard deviation (SD) obtained on three replicates.

$977 \mathrm{~d} 0=$ day $0 ; \mathrm{d} 13=$ day 13

978 
979 Table 4. Cytochrome P450 activities of primary human hepatocytes $(\mathrm{PHH})$ from the three donors used 980 for the biokinetic studies.

\begin{tabular}{lccccc} 
& \multicolumn{5}{c}{ Activity in pmol/min/mg protein } \\
\cline { 2 - 6 } Donor & CYP1A1/2 & CYP2B6 & CYP3A4 & CYP2C9 & CYP2D6 \\
\hline B1032 & $<$ LOQ & 5.33 & 0.104 & 3.81 & 0.281 \\
S1045 & 0.221 & 23.1 & 33.4 & 29.9 & 3.36 \\
B1050 & 0.140 & 22.1 & $<$ LOQ & 15.1 & 0.809 \\
\hline
\end{tabular}

981

982 The specific activity of cytochrome P450s (CYP) in the hepatocyte preparations deriving from the 983 three different donors was assessed one day after seeding. Results were expressed as average of 984 two technical replicates.

985 
986 Table 5. Summary statistics of the posterior "population" mean parameters distribution of the in vitro 987 ibuprofen (IBU) kinetic models in the three cellular systems.

988

\begin{tabular}{|c|c|c|c|}
\hline Parameter & PRH values $^{\text {a }}$ & PHH values & HepaRG cell values \\
\hline $\mathrm{F}_{\text {in }}$ & $230 \pm 25[180,290]$ & $259 \pm 75[130,440]$ & $-d$ \\
\hline $\mathrm{F}_{\text {out }}$ & $24 \pm 2.9[17,30]$ & $45.8 \pm 15[23,84]$ & $-d$ \\
\hline $\mathrm{k}_{1}$ & $\begin{array}{c}3.5 \times 10^{-4} \pm 7.4 \times 10^{-5} \\
{\left[2 \times 10^{-4}, 5.2 \times 10^{-5}\right]}\end{array}$ & $-d$ & $-d$ \\
\hline $\mathrm{k}_{2}$ & $\begin{array}{l}1.4 \times 10^{-3} \pm 3.3 \times 10^{-4} \\
{\left[7.4 \times 10^{-4}, 2.2 \times 10^{-3}\right]}\end{array}$ & $-d$ & $-d$ \\
\hline $\mathrm{V}_{\max }$ & $-b$ & $\begin{array}{l}5.7 \times 10^{-9} \pm 3 \times 10^{-9} \\
{\left[2.2 \times 10^{-9}, 1.4 \times 10^{-8}\right]}\end{array}$ & $-b$ \\
\hline $\mathrm{V}_{\max } / \mathrm{K}_{\mathrm{m}}$ & $0.47 \pm 0.02[0.42,0.5]$ & $6.5 \pm 3.0[3.0,15]$ & $13 \pm 6.5[5.4,30]$ \\
\hline$\alpha$ & $-{ }^{c}$ & $-c$ & $\begin{array}{l}5.1 \times 10^{-7} \pm 1.4 \times 10^{-7} \\
{\left[2.5 \times 10^{-7}, 8 \times 10^{-7}\right]}\end{array}$ \\
\hline
\end{tabular}

989

990 These posterior distributions were obtained by model calibration with the data. For $\mathrm{PRH}$ they 991 characterise to a typical experiment; while for $\mathrm{PHH}$ they correspond to the geometric mean of a virtual 992 population of hypothetical donors. For HepaRG cells they represent the geometric mean of a virtual 993 set of experiments.

994 a (mean \pm SD) [2.5 and 97.5 percentiles of the posterior distribution].

995 b not applicable (first order kinetics).

$996{ }^{\mathrm{c}}$ not applicable (slope set to zero).

$997{ }^{d}$ not applicable (fixed value parameter).

998 


\section{Supplementary Data}

1000 Table S1. Population mean parameters descriptions, set values or statistical distributions of the in vitro 1001 IBU kinetic model for $\mathrm{PHH}$. The posterior distributions were obtained by model calibration with the 1002 data and represent the geometric mean of a virtual population of hypothetical donors.

\begin{tabular}{|c|c|c|c|}
\hline Parameter & Description & Units & Value or Prior distribution \\
\hline $\mathrm{N}_{\text {cell }}$ & number of hepatocytes & - & $2 \times 10^{6}$ \\
\hline $\mathrm{V}_{\text {med }}$ & volume of assay medium & $\mu \mathrm{m}^{3}$ & $2 \times 10^{12}$ \\
\hline $\mathrm{V}_{\text {cell }}$ & volume of a cell & $\mu m^{3}$ & $3400^{c}$ \\
\hline $\mathrm{F}_{\text {in }}$ & cell entry rate flow ${ }^{a}$ & $\mu \mathrm{m}^{3} \cdot \mathrm{sec}^{-1}$ & $U(0,500)^{d}$ \\
\hline$F_{\text {out }}$ & cell exit rate flow ${ }^{a}$ & $\mu \mathrm{m}^{3} \cdot \sec ^{-1}$ & $U\left(0,10^{6}\right)$ \\
\hline $\mathrm{k}_{1}$ & GelTrex ${ }^{\mathrm{TM}}$ binding rate constant & $\sec ^{-1}$ & 0 \\
\hline $\mathrm{k}_{2}$ & GelTrex ${ }^{\mathrm{TM}}$ unbinding rate constant & $\sec ^{-1}$ & 0 \\
\hline $\mathrm{V}_{\max }$ & maximum rate of metabolism ${ }^{a}$ & nmol.sec ${ }^{-1}$ & $U\left(0,10^{-7}\right)$ \\
\hline $\mathrm{V}_{\max } / \mathrm{K}_{\mathrm{m}}$ & low-dose metabolic clearance ${ }^{a, b}$ & $\mu \mathrm{m}^{3} \cdot \sec ^{-1}$ & $U\left(0,10^{6}\right)$ \\
\hline
\end{tabular}

${ }^{a}$ Per hepatocyte.

$1004{ }^{\mathrm{b}}$ At each iteration, $\mathrm{V}_{\max }$ was divided by this parameter to compute the $\mathrm{K}_{\mathrm{m}}$ value to use in Eq. 5.

$1005{ }^{\mathrm{c}}$ Lodish et al., 2000.

$1006{ }^{d} U(\min , \max )$ : uniform distribution. 
1008 Table S2. Population mean parameters descriptions, set values or statistical distributions of the in vitro 1009 IBU kinetic model for HepaRG cells. The posterior distributions were obtained by model calibration 1010 with the data and represent the geometric mean of a virtual set of experiments.

\begin{tabular}{|c|c|c|c|}
\hline Parameter & Description & Units & Value or Prior distribution \\
\hline $\mathrm{N}_{\text {cell }}$ & number of hepatocytes & - & $10^{6}$ \\
\hline $\mathrm{V}_{\text {med }}$ & volume of assay medium & $\mu \mathrm{m}^{3}$ & $2 \times 10^{12}$ \\
\hline $\mathrm{V}_{\text {cell }}$ & volume of a cell & $\mu \mathrm{m}^{3}$ & $3400^{b}$ \\
\hline $\mathrm{F}_{\text {in }}$ & cell entry rate flow ${ }^{a}$ & $\mu m^{3} \cdot \sec ^{-1}$ & 150 \\
\hline $\mathrm{F}_{\text {out }}$ & cell exit rate flow ${ }^{a}$ & $\mu m^{3} \cdot \sec ^{-1}$ & 30 \\
\hline $\mathrm{k}_{1}$ & protein binding rate constant & $\sec ^{-1}$ & 0 \\
\hline $\mathrm{k}_{2}$ & protein unbinding rate constant & $\sec ^{-1}$ & 0 \\
\hline $\mathrm{V}_{\max }\left(\mathrm{t}_{0}\right) / \mathrm{K}_{\mathrm{m}}$ & initial metabolic clearance $^{a}$ & $\mu m^{3} \cdot \sec ^{-1}$ & $U\left(0,10^{6}\right)^{c}$ \\
\hline$\alpha$ & clearance slope factor & $\sec ^{-1}$ & $U\left(0,10^{-6}\right)$ \\
\hline $\mathrm{N}_{\text {bcell }}$ & number of biliary cells & - & $10^{6}$ \\
\hline
\end{tabular}

1011 a Per cell.

$1012{ }^{b}$ Lodish et al., 2000.

$1013{ }^{\mathrm{c}} \cup(\min , \max )$ : uniform distribution. 